\title{
Reversible Self-Assembly of Water-Soluble Gold(I) Complexes
}

\author{
Elisabet Aguiló, ${ }^{\dagger}$ Artur J. Moro, ${ }^{\ddagger}$ Raquel Gavara, ${ }^{\dagger}$ Ignacio Alfonso, ${ }^{\S \odot}$ Yolanda Pérez, ${ }^{\| \bullet}$
} Francesco Zaccaria, ${ }^{\perp}$ Célia Fonseca Guerra, ${ }^{\perp, \#}$ Marc Malfois, ${ }^{\text {TI }}$ Clara Baucells, ${ }^{\dagger}$ Montserrat Ferrer, ${ }^{\dagger}$ João Carlos Lima, ${ }^{*} \neq \odot$ and Laura Rodríguez ${ }^{*}, t, \nabla \odot$

\author{
${ }^{\dagger}$ Departament de Química Inorgànica i Orgànica, Secció de Química Inorgànica, Universitat de Barcelona, Martí i Franquès 1-11, \\ 08028 Barcelona, Spain \\ ${ }^{\ddagger}$ LAQV-REQUIMTE, Departamento de Química, CQFB, Universidade Nova de Lisboa, 2829-516 Monte de Caparica, Portugal \\ ${ }^{\S}$ Departamento de Química Biológica y Modelización Molecular and "NMR Facility, IQAC-CSIC, Jordi Girona 16-26, E-08034 \\ Barcelona, Spain \\ ${ }^{\perp}$ Department of Theoretical Chemistry, Amsterdam Center for Multiscale Modeling, $1081 \mathrm{HV}$ Amsterdam, The Netherlands \\ \#Leiden Institute of Chemistry, Gorlaeus Laboratories, Leiden University, 2311 EZ Leiden, The Netherlands \\ ${ }^{I}$ ALBA Synchrotron Light Laboratory (CELLS), Carrer de la Llum 2-26, 08290 Cerdanyola del Vallès, Barcelona, Spain

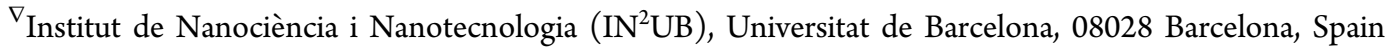

\section{Supporting Information}

ABSTRACT: The reaction of the gold polymers containing bipyridyl and terpyridyl units, $\left[\mathrm{Au}\left(\mathrm{C} \equiv \mathrm{CC}_{15} \mathrm{H}_{10} \mathrm{~N}_{3}\right)\right]_{n}$ and $[\mathrm{Au}(\mathrm{C} \equiv$ $\left.\left.\mathrm{CC}_{10} \mathrm{H}_{7} \mathrm{~N}_{2}\right)\right]_{n}$, with the water-soluble phosphines 1,3,5-triaza-7phosphatricyclo[3.3.1.13.7] decane and 3,7-diacetyl-1,3,7-triaza-5phosphabicyclo[3.3.1] nonane gives rise to the formation of four gold(I) alkynyl complexes that self-assemble in water $\left(\mathrm{H}_{2} \mathrm{O}\right)$ and dimethyl sulfoxide (DMSO), through different intermolecular interactions, with an impact on the observed luminescence displayed by the supramolecular assemblies. A detailed analysis carried out by NMR studies performed in different DMSO/deuterated $\mathrm{H}_{2} \mathrm{O}$ mixtures

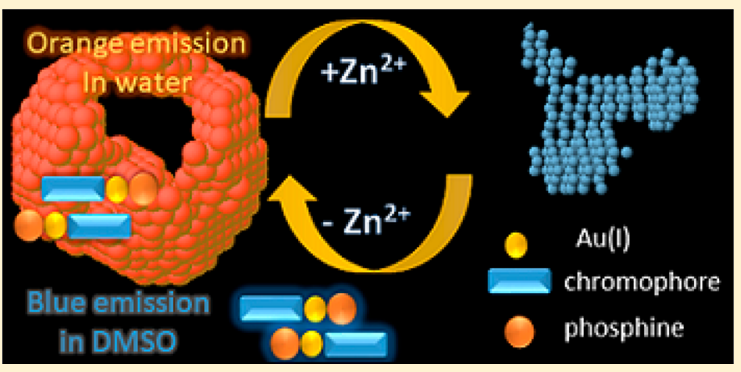
indicates the presence of two different assembly modes in the aggregates: (i) chain assemblies, which are based mainly on aurophilic interactions, and (ii) stacked assemblies, which are based on $\mathrm{Au} \cdots \pi$ and $\pi \cdots \pi$ interactions. These different supramolecular environments can also be detected by their intrinsic optical properties (differences in absorption and emission spectra) and are predicted by the changes in the relative binding energy from density functional theory calculations carried out in DMSO and $\mathrm{H}_{2} \mathrm{O}$. Small-angle X-ray scattering (SAXS) experiments performed in the same mixture of solvents are in agreement with the formation of aggregates in all cases. The aromatic units chosen, bipyridine and terpyridine, allow the use of external stimuli to reversibly change the aggregation state of the supramolecular assemblies. Interaction with the $\mathrm{Zn}^{2+}$ cation is observed to disassemble the aggregates, while encapsulating agents competing for $\mathrm{Zn}^{2+}$ complexation revert the process to the aggregation stage, as verified by SAXS and NMR. The adaptive nature of the supramolecular assemblies to the metal-ion content is accompanied by significant changes in the absorption and emission spectra, signaling the aggregation state and also the content on $\mathrm{Zn}^{2+}$.

\section{INTRODUCTION}

The self-assembly of small molecules by the establishment of noncovalent interactions has received great attention in the past decade as a way to build supramolecular structures with a large number of specific functions and morphologies. ${ }^{1-4}$ As a result, supramolecular chemistry has matured from a conceptually marvelous scientific curiosity to a technologically relevant science encompassing a broad area of advanced materials. ${ }^{5}$ Within this field, gold(I) complexes represent an emerging area of investigation in the last years because they show weak $\mathrm{Au}^{\mathrm{I}}$... $\mathrm{Au}^{\mathrm{I}}$ interactions that can modulate and govern the resulting assemblies and properties in very different potential applications. ${ }^{6,7}$ It was recently shown that small molecules of the type R-gold(I) alkynylpyridine, where $\mathrm{R}$ is a water-soluble phosphine (compounds A and $\mathbf{B}$ in Chart 1), self-assemble to form long fibers and hydrogels through intermolecular $\pi$ stacking and metallophilic interactions. ${ }^{8,9}$ Replacing the pyridine moiety by a different aromatic unit such as coumarin (compound $\mathbf{C}$ in Chart 1) does not hamper the assembling ability of these molecules. ${ }^{10}$ On the other hand, the introduction of a positive charge on the chemical structure either at the phosphine (complexes 1 and $\mathbf{4}$ in Chart 1) or at the pyridyl unit (complexes $2,3,5$, and 6) switches the fibrillary self-assembly into rods, spherical vesicles, or squarelike morphologies. $^{11}$

Received: September 12, 2017

Published: October 28, 2017 
Chart 1. Molecular Structures of the Gold(I) Alkynyl Complexes Previously Studied
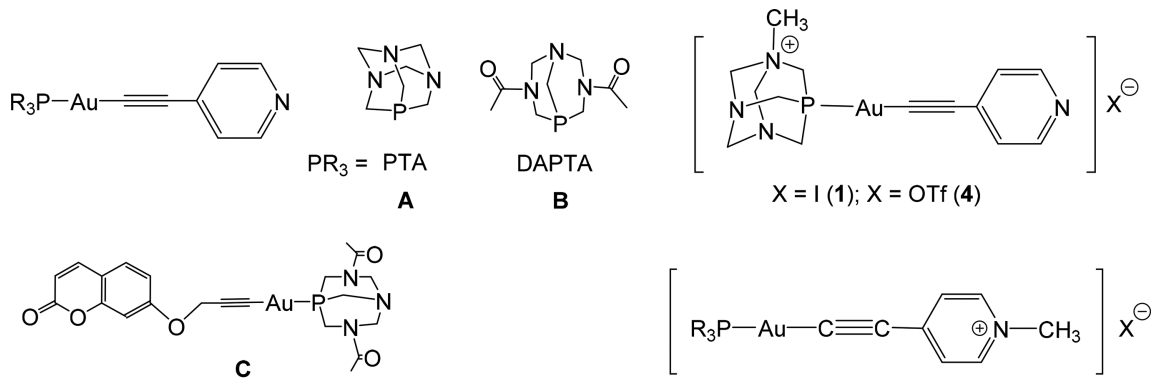

$\mathrm{PR}_{3}=\mathrm{PTA}, \mathrm{X}=\mathrm{I}(\mathbf{2}) ; \mathrm{X}=\mathrm{OTf}(\mathbf{5})$

$\mathrm{PR}_{3}=\mathrm{DAPTA}, \mathrm{X}=\mathrm{I}(\mathbf{3}) ; \mathrm{X}=\mathrm{OTf}(\mathbf{6})$

Novel supramolecular nanostructures constituted by the noncovalent self-organization of small metallophilic molecules with tunable properties are underexplored within the field of self-assembling materials. Research interest has increased in the last years in the construction of stimuli-responsive metallosupramolecular architectures with diverse sizes, shapes, and symmetries because of their promising applications such as molecular transporting devices, chemosensors, optoelectronic devices, drug delivery, tissue engineering, biomaterials, surface science, displays, etc. ${ }^{5,12-16}$ Stimuli-responsive systems are capable of modulating their behavior in a differential manner depending on the external stimulus to which they are exposed, being a considerable challenge for supramolecular chemists.

The modular chemistry of gold(I) alkynyl complexes, furthermore, allows for a rational design where solubility and function can be added to program the supramolecular assembly into nanostructures that can be tuned by changes in the charge or polarity, among others.

In this work, we extend the development of these small molecules by adding a chelating unit able to trigger the assembly/disassembly process by external stimuli (e.g., cations and chelating molecules). At the same time, the increase in the number of aromatic rings will allow a change in the balance between $\mathrm{Au} \cdots \mathrm{Au}$ and $\pi \cdots \pi$ interactions, which will impact the stability of the aggregates. Complexation with cations will significantly change the electrostatic balance of the assemblies, leading to dissociation. The disassembly can be reversed by the addition of molecules that compete for the metal cation, leading to reassembly of the nanostructures.

\section{EXPERIMENTAL SECTION}

General Procedures. All manipulations have been performed under prepurified $\mathrm{N}_{2}$ using standard Schlenk techniques. All solvents have been distilled from appropriated drying agents. Commercial reagents 1,3,5-triaza-7-phosphatricyclo[3.3.1.13.7] decane (PTA; 97\%, Aldrich) and 3,7-diacetyl-1,3,7-triaza-5-phosphabicyclo[3.3.1] nonane (DAPTA; 97\%, Aldrich) have been used as received. Literature methods have been used to prepare 5-ethynyl-2,2'-bipyridine, ${ }^{17} 4^{\prime}$ ethynyl-2,2', $6^{\prime}, 2^{\prime \prime}$-terpyridine, ${ }^{18}\left[\mathrm{Au}\left(\mathrm{C} \equiv \mathrm{CC}_{15} \mathrm{H}_{10} \mathrm{~N}_{3}\right)\right]_{n},{ }^{19}$ and $\left[\mathrm{Au}\left(\mathrm{C} \equiv \mathrm{CC}_{10} \mathrm{H}_{7} \mathrm{~N}_{2}\right)\right]_{n}$.

Physical Measurements. IR spectra have been recorded on a Nicolet 520 Fourier transform infrared spectrophotometer. ${ }^{1} \mathrm{H}$ $[\delta(\mathrm{TMS})=0.0 \mathrm{ppm}]$ and ${ }^{31} \mathrm{P}\left\{{ }^{1} \mathrm{H}\right\}\left[\delta\left(85 \% \mathrm{H}_{3} \mathrm{PO}_{4}\right)=0.0 \mathrm{ppm}\right]$ NMR spectra have been obtained on Varian Mercury 400 and Bruker 400 spectrometers. One- and two-dimensional (1D and 2D) NMR experiments were performed also at $298 \mathrm{~K}$ on a $500 \mathrm{MHz}$ Bruker AVANCEIII-HD spectrometer equipped with a $z$-gradient $(65.7 \mathrm{G} /$ $\mathrm{cm}$ ) inverse TCI cryoprobe. The gradient strength was calibrated using the diffusion coefficient of water $\left(\mathrm{H}_{2} \mathrm{O}\right)$ in a standard solution of 0.1 $\mathrm{mg} / \mathrm{mL} \mathrm{GdCl} 3,0.1 \%$ 4,4-dimethyl-4-silapentane-1-sulfonic acid, and
$1 \% \mathrm{H}_{2} \mathrm{O}$ in deuterated $\mathrm{H}_{2} \mathrm{O}\left(\mathrm{D}_{2} \mathrm{O}\right)$. Samples $\mathbf{2} \mathbf{a}$ and $\mathbf{2} \mathbf{b}$ were dissolved in the corresponding deuterated solvent containing 3-(trimethylsilyl)propionic-2,2,3,3- $d_{4}$ acid sodium salt (TSP- $\left.d_{4}\right)$. TSP- $d_{4}$ was used as an internal standard both for calibrating the ${ }^{1} \mathrm{H}$ and ${ }^{13} \mathrm{C}$ chemical shifts and for estimating the relative concentration changes upon aggregation. Bruker TopSpin 3.5pl6 standard pulse sequences were used for the $1 \mathrm{D}$ and $2 \mathrm{D}$ experiments. To obtain the highest receiver gain and to apply the minimum amount of scans and increments using low sample concentrations $(\leq 1 \mathrm{mM})$, the reduction of residual water in the NMR spectra (coming from the sample and/or on deuterated solvents) was needed, so pulse sequences with a soft suppression of the water resonance were used. $1 \mathrm{D}{ }^{1} \mathrm{H}$ NMR experiments were acquired using the zgesgppe pulse sequence, which incorporates water suppression using excitation sculpting with gradients and perfect echo. For $2 \mathrm{D}{ }^{1} \mathrm{H}-{ }^{1} \mathrm{H}$ NMR experiments, excitation sculpting for ${ }^{1} \mathrm{H}-{ }^{1} \mathrm{H}$ NOESY (noesyesgpph pulse program) and 3-9-19 pulse train for DOSY (stebpgp1s19 pulse program) were applied for water suppression. $2 \mathrm{D}{ }^{1} \mathrm{H}-{ }^{13} \mathrm{C}$ (HSQC and $\mathrm{HMBC}$ ) experiments were also acquired. Spin-lattice $\left(T_{1}\right)$ and spin-spin $\left(T_{2}\right)$ relaxation times were measured for complex $\mathbf{2 b}$ using a standard inversion-recovery pulse sequence for $T_{1}$ and PROJECT-CPMG ${ }^{21}$ for $T_{2}$.

2D DOSY ${ }^{22}$ experiments were performed using a stimulated-echo sequence incorporating bipolar gradient pulses and one spoil gradient. The gradient strength was logarithmically incremented in 18-24 steps from 5 to $98 \%$ of its maximum value. Diffusion times and gradient pulse durations were optimized for each experiment. Typically, diffusion times between 60 and $120 \mathrm{~ms}$ and bipolar rectangular gradient pulses of $2.0 \mathrm{~ms}$ were employed. Diffusion NMR data were processed and represented using the free software DOSY Toolbox. ${ }^{23}$ The translational diffusion coefficient obtained for different samples was used to estimate the "apparent" sizes of the gold(I) complexes in different solvent compositions. For calculation of the hydrodynamic radii, the diffusion coefficients were obtained from the monoexponential fitting of the integral values versus gradient strength using the TopSpin 3.5 pl6 relaxation module. When calculating and interpreting the values of the hydrodynamic radii, we have taken into account two facts: (1) the Stokes-Einstein equation is only valid for spherical particles with sizes larger that the solvent molecules; (2) the effects of chemical exchange in diffusion spectra. ${ }^{22}$ In our case, for DMSO- $d_{6}$ and DMSO- $d_{6}$ with low amounts of $\mathrm{D}_{2} \mathrm{O}$, we expected to have mainly monomer or dimer molecules in solutions, so our gold(I) complexes have slightly larger sizes than the solvent. Therefore, for our $r_{\mathrm{H}}$ calculations, we followed the method described by Macchioni et al. ${ }^{24}$ using the expression of factor $c$ as a function of $r_{\text {solv }} / r_{\mathrm{H}}$ derived by Chen et $\mathrm{al}^{25}$ and the approximation that our complexes were spherical.

Positive-mode electrospray ionization mass spectrometry [ESIMS(+)] spectra were recorded on a Fisons VG Quatro spectrometer. Absorption spectra were recorded on a Varian Cary 100 Bio UV spectrophotometer and emission spectra on Horiba-Jobin-Ybon SPEX Fluorolog 3.22 and Nanolog spectrofluorimeters. Fluorescence microscopy was recorded on a Zeiss Axioplan 2ie imaging microscope equipped with a Nikon DXM1200F digital camera and a Leica DMIRB 
fluorescence microscope. Optical microscopy images were acquired on a Leica ICC50 W microscope. Dynamic light scattering (DLS) measurements were carried out on a Horiba SZ-100 nanoparticle analyzer instrument operating at $22^{\circ} \mathrm{C}$.

Small-Angle X-ray Scattering (SAXS). SAXS was performed on the NCD beamline at the ALBA Synchrotron at $12.4 \mathrm{keV}$, and the distance sample/detector was $2.2 \mathrm{~m}$ to cover the range of momentum transfer of $0.09<q\left(\mathrm{~nm}^{-1}\right)<5.6$. The data were collected on an ImXPad S1400 detector with a pixel size of $130.0 \times 130.0 \mu \mathrm{m}^{2}$. The exposure time was $10 \mathrm{~s}$. The $q$-axis calibration was obtained by measuring silver behenate. ${ }^{26}$ The program $p y F A I^{27}$ was used to integrate the 2D SAXS data into 1D data.

The data were then subtracted by the background using PRIMUS software. ${ }^{28}$ The maximum particle dimension $D_{\max }$ and the pairdistance distribution function $P(r)$ were determined with $G N O M{ }^{29}$ The low-resolution structure of the aggregates was reconstructed $a b$ initio from the initial portions of the scattering patterns using the program DAMMIN. ${ }^{30}$

Solutions of $1 \times 10^{-4}$ and $1 \times 10^{-5} \mathrm{M}$ of complexes $1 \mathrm{a}, \mathbf{1 b}, \mathbf{2 a}$, and 2b were prepared in different $\mathrm{H}_{2} \mathrm{O}$ /dimethyl sulfoxide (DMSO) mixtures of $0 \% \mathrm{H}_{2} \mathrm{O}$ to $100 \%(0,25,50,75$, and $90 \%)$ DMSO.

Synthesis of $\left[\mathrm{Au}\left(\mathrm{C} \equiv \mathrm{CC}_{15} \mathrm{H}_{10} \mathrm{~N}_{3}\right)(\mathrm{PTA})\right]$ (1a). Solid PTA (21 mg, $0.13 \mathrm{mmol})$ was added to a suspension of $\left[\mathrm{Au}\left(\mathrm{C} \equiv \mathrm{CC}_{15} \mathrm{H}_{10} \mathrm{~N}_{3}\right)\right]_{n}(60$ $\mathrm{mg}, 0.13 \mathrm{mmol})$ in $\mathrm{CH}_{2} \mathrm{Cl}_{2}(20 \mathrm{~mL})$. After $45 \mathrm{~min}$ of stirring at room temperature, the resulting pale-yellow solution was concentrated (5 $\mathrm{mL})$, and $n$-hexane $(15 \mathrm{~mL})$ was added to precipitate a pale-yellow solid (66 mg, 81\%). ${ }^{31} \mathrm{P}$ NMR (161.9 MHz, $\left.\mathrm{CDCl}_{3}, \mathrm{ppm}\right):-12.8 .{ }^{1} \mathrm{H}$ NMR $\left(400 \mathrm{MHz}, \mathrm{CDCl}_{3}, 298 \mathrm{~K}, \mathrm{ppm}\right): 8.62(\mathrm{dq}, J=4.8 \mathrm{~Hz}, J=0.8$ $\left.\mathrm{Hz}, 2 \mathrm{H}, \mathrm{H}_{9}\right), 8.53\left(\mathrm{dt}, J=12.0 \mathrm{~Hz}, J=1.2 \mathrm{~Hz}, 2 \mathrm{H}, \mathrm{H}_{12}\right), 8.46(\mathrm{~s}, 2 \mathrm{H}$, $\left.\mathrm{H}_{3}+\mathrm{H}_{5}\right), 7.84\left(\mathrm{td}, J=11.9 \mathrm{~Hz}, J=1.4 \mathrm{~Hz}, 2 \mathrm{H}, \mathrm{H}_{11}\right), 7.30$ (ddd, $J=$ $\left.12.0 \mathrm{~Hz}, J=4.8 \mathrm{~Hz}, 2 \mathrm{H}, \mathrm{H}_{10}\right), 4.60-4.48(\mathrm{AB} \mathrm{q}, J=13.0 \mathrm{~Hz}, 6 \mathrm{H}$, $\left.\mathrm{NCH}_{2} \mathrm{~N}\right), 4.30\left(\mathrm{~s}, 6 \mathrm{H}, \mathrm{NCH}_{2} \mathrm{P}\right)$. IR $\left(\mathrm{KBr}, \mathrm{cm}^{-1}\right): 3425(\mathrm{C}-\mathrm{H}), 2114$ $(\mathrm{C} \equiv \mathrm{C}), 1636(\mathrm{C}=\mathrm{N})$. ESI-MS $(+): m / z 611.137\left(\left[\mathrm{M}+\mathrm{H}^{+}\right]^{+}\right.$; calcd $m / z$ 611.139), $1243.250\left(\left[2 \mathrm{M}+\mathrm{Na}^{+}\right]^{+}\right.$; calcd $m / z$ 1243.252).

Synthesis of $\left[\mathrm{Au}\left(\mathrm{C} \equiv \mathrm{CC}_{15} \mathrm{H}_{10} \mathrm{~N}_{3}\right)(\mathrm{DAPTA})\right]$ (1b). Solid DAPTA (30 $\mathrm{mg}, 0.13 \mathrm{mmol})$ was added to a suspension of $\left[\mathrm{Au}\left(\mathrm{C} \equiv \mathrm{CC}_{15} \mathrm{H}_{10} \mathrm{~N}_{3}\right)\right]_{n}$ $(60 \mathrm{mg}, 0.13 \mathrm{mmol})$ in $\mathrm{CH}_{2} \mathrm{Cl}_{2}(20 \mathrm{~mL})$. After $45 \mathrm{~min}$ of stirring at room temperature, the resulting pale-yellow solution was concentrated $(10 \mathrm{~mL})$, and $n$-hexane $(10 \mathrm{~mL})$ was added to precipitate a pale-yellow solid (75 mg, 85\%). ${ }^{31} \mathrm{P} \mathrm{NMR}\left(161.9 \mathrm{MHz}, \mathrm{CDCl}_{3}, \mathrm{ppm}\right):-10.2 .{ }^{1} \mathrm{H}$ NMR $\left(400 \mathrm{MHz}, \mathrm{CDCl}_{3}, \mathrm{ppm}\right): 8.68(\mathrm{dq}, J=5.0 \mathrm{~Hz}, J=0.8 \mathrm{~Hz}, 2 \mathrm{H}$, $\left.\mathrm{H}_{9}\right), 8.56\left(\mathrm{dt}, J=12.0 \mathrm{~Hz}, J=0.8 \mathrm{~Hz}, 2 \mathrm{H}, \mathrm{H}_{12}\right), 8.48\left(\mathrm{~s}, 2 \mathrm{H}, \mathrm{H}_{3}+\mathrm{H}_{5}\right)$, $7.82\left(\mathrm{td}, J=11.8 \mathrm{~Hz}, J=1.6 \mathrm{~Hz}, 2 \mathrm{H}, \mathrm{H}_{11}\right), 7.30(\mathrm{ddd}, J=12.0 \mathrm{~Hz}, J=$ $\left.4.8 \mathrm{~Hz}, 2 \mathrm{H}, \mathrm{H}_{10}\right), 5.78\left(\mathrm{~d}, J=20.0 \mathrm{~Hz}, 1 \mathrm{H}, \mathrm{H}_{19 a}, \mathrm{NCH}_{2} \mathrm{~N}\right), 5.66(\mathrm{dd}, J$ $\left.=20.0 \mathrm{~Hz}, J=12.0 \mathrm{~Hz}, 1 \mathrm{H}, \mathrm{H}_{23 a}, \mathrm{NCH}_{2} \mathrm{P}\right), 4.94(\mathrm{~d}, J=16.0 \mathrm{~Hz}, 1 \mathrm{H}$, $\left.\mathrm{H}_{21 \mathrm{a}}, \mathrm{NCH}_{2} \mathrm{~N}\right), 4.70-4.64\left(\mathrm{~m}, 2 \mathrm{H}, \mathrm{H}_{17 a}, \mathrm{NCH}_{2} \mathrm{P},+\mathrm{H}_{21 \mathrm{~b}}, \mathrm{NCH}_{2} \mathrm{~N}\right)$, $4.15\left(\mathrm{dt}, J=20.0 \mathrm{~Hz}, J=4.0 \mathrm{~Hz}, 1 \mathrm{H}, \mathrm{H}_{17 \mathrm{~b}}, \mathrm{NCH}_{2} \mathrm{P}\right), 4.06(\mathrm{~d}, J=20.0$ $\left.\mathrm{Hz}, 1 \mathrm{H}, \mathrm{H}_{19 \mathrm{~b}}, \mathrm{NCH}_{2} \mathrm{~N}\right), 3.87\left(\mathrm{~s}, 2 \mathrm{H}, \mathrm{H}_{24}, \mathrm{NCH}_{2} \mathrm{P}\right), 3.57(\mathrm{dt}, J=20.0 /$ $\left.4.0 \mathrm{~Hz}, 1 \mathrm{H}, \mathrm{H}_{23 \mathrm{~b}}, \mathrm{NCH}_{2} \mathrm{P}\right), 2.17\left(\mathrm{~s}, 6 \mathrm{H}, \mathrm{COCH}_{3}\right)$. IR $\left(\mathrm{KBr}, \mathrm{cm}^{-1}\right)$ : $3441(\mathrm{C}-\mathrm{H}), 2116(\mathrm{C} \equiv \mathrm{C}), 1640(\mathrm{C}=\mathrm{N})$. ESI-MS $(+): m / z 683.158$ $\left([\mathrm{M}+\mathrm{H}]^{+}\right.$; calcd $\left.m / z 683.160\right), 705.139\left([\mathrm{M}+\mathrm{Na}]^{+}\right.$; calcd $\mathrm{m} / z$ 705.142).

Synthesis of $\left[\mathrm{Au}\left(\mathrm{C} \equiv \mathrm{CC}_{10} \mathrm{H}_{7} \mathrm{~N}_{2}\right)(\mathrm{PTA})\right]$ (2a). Solid PTA (25 mg, $0.16 \mathrm{mmol})$ was added to a suspension of $\left[\mathrm{Au}\left(\mathrm{C} \equiv \mathrm{CC}_{10} \mathrm{H}_{7} \mathrm{~N}_{2}\right)\right]_{n}(60$ $\mathrm{mg}, 0.16 \mathrm{mmol})$ in $\mathrm{CH}_{2} \mathrm{Cl}_{2}(20 \mathrm{~mL})$. After $45 \mathrm{~min}$ of stirring at room temperature, the resulting yellow solution was concentrated $(10 \mathrm{~mL})$, and $n$-hexane $(10 \mathrm{~mL})$ was added to precipitate a pale-yellow solid $(77$ mg, 90\%). ${ }^{31} \mathrm{P}$ NMR (161.9 MHz, $\left.\mathrm{CDCl}_{3}, \mathrm{ppm}\right):-48.2 .{ }^{1} \mathrm{H}$ NMR $\left(400 \mathrm{MHz}, \mathrm{CDCl}_{3}, \mathrm{ppm}\right): 8.73\left(\mathrm{~d}, J=5.0 \mathrm{~Hz}, 1 \mathrm{H}, \mathrm{H}_{9}\right), 8.65(\mathrm{dd}, J=$ $\left.12.0 \mathrm{~Hz}, J=0.8 \mathrm{~Hz}, 1 \mathrm{H}, \mathrm{H}_{6}\right), 8.36(\mathrm{dt}, J=12.0 \mathrm{~Hz}, J=4.8 \mathrm{~Hz}, 1 \mathrm{H}$, $\left.\mathrm{H}_{12}\right), 8.29\left(\mathrm{dd}, J=8.4 \mathrm{~Hz}, J=2.5 \mathrm{~Hz}, 1 \mathrm{H}, \mathrm{H}_{3}\right), 7.80(\mathrm{~m}, J=8.0 \mathrm{~Hz}, J=$ $1.6 \mathrm{~Hz}, 2 \mathrm{H}, \mathrm{H}_{4}+\mathrm{H}_{11}$ ), 7.27 (ddd, $J=8.0 \mathrm{~Hz}, J=4.0 \mathrm{~Hz}, J=2.0 \mathrm{~Hz}$, $\left.1 \mathrm{H}, \mathrm{H}_{10}\right), 4.60-4.48\left(\mathrm{AB} \mathrm{q}, J=13.0 \mathrm{~Hz}, 6 \mathrm{H}, \mathrm{H}_{19 \mathrm{~b}}, \mathrm{NCH}_{2} \mathrm{~N}\right), 4.30(\mathrm{~s}$, $\left.6 \mathrm{H}, \mathrm{NCH}_{2} \mathrm{P}\right)$. IR $\left(\mathrm{KBr}, \mathrm{cm}^{-1}\right): 3425(\mathrm{C}-\mathrm{H}), 2104(\mathrm{C} \equiv \mathrm{C}), 1640$ $(\mathrm{C}=\mathrm{N})$. ESI-MS $(+): m / z 534.111\left(\left[\mathrm{M}+\mathrm{H}^{+}\right]^{+}\right.$; calcd $\left.m / z 534.112\right)$, $556.092\left(\left[\mathrm{M}+\mathrm{Na}^{+}\right]^{+}\right.$; calcd $m / z$ 556.094).

Synthesis of $\left[\mathrm{Au}\left(\mathrm{C} \equiv \mathrm{C}-\mathrm{C}_{10} \mathrm{H}_{7} \mathrm{~N}_{2}\right)(\right.$ DAPTA) $]$ (2b). Solid DAPTA (36 $\mathrm{mg}, 0.16 \mathrm{mmol})$ was added to a suspension of $\left[\mathrm{Au}\left(\mathrm{C} \equiv \mathrm{CC}_{10} \mathrm{H}_{7} \mathrm{~N}_{2}\right)\right]_{n}$ $(60 \mathrm{mg}, 0.16 \mathrm{mmol})$ in $\mathrm{CH}_{2} \mathrm{Cl}_{2}(20 \mathrm{~mL})$. After $45 \mathrm{~min}$ of stirring at room temperature, the resulting yellow solution was concentrated (10
$\mathrm{mL})$, and $n$-hexane $(10 \mathrm{~mL})$ was added to precipitate a pale-yellow solid (82 mg, 85\%). ${ }^{31} \mathrm{P}$ NMR (161.9 MHz, $\left.\mathrm{CDCl}_{3}, \mathrm{ppm}\right):-23.0 .{ }^{1} \mathrm{H}$ NMR $\left(400 \mathrm{MHz}, \mathrm{CDCl}_{3}, \mathrm{ppm}\right): 8.75(\mathrm{dd}, J=4.0 \mathrm{~Hz}, J=0.6 \mathrm{~Hz}, 1 \mathrm{H}$, $\left.\mathrm{H}_{9}\right), 8.66\left(\mathrm{dd}, J=8.0 \mathrm{~Hz}, J=0.8 \mathrm{~Hz}, 1 \mathrm{H}, \mathrm{H}_{6}\right), 8.37(\mathrm{dt}, J=12.0 \mathrm{~Hz}, J$ $\left.=0.8 \mathrm{~Hz}, 1 \mathrm{H}, \mathrm{H}_{12}\right), 8.32\left(\mathrm{dd}, J=11.8 \mathrm{~Hz}, J=0.4 \mathrm{~Hz}, 1 \mathrm{H}, \mathrm{H}_{3}\right), 7.82$ $\left(\mathrm{m}, 2 \mathrm{H}, \mathrm{H}_{4}+\mathrm{H}_{11}\right.$ ), 7.28 (ddd, $J=12.0 \mathrm{~Hz}, J=7.2 \mathrm{~Hz}, J=0.6 \mathrm{~Hz}, 1 \mathrm{H}$, $\left.\mathrm{H}_{10}\right), 5.78\left(\mathrm{~d}, J=20.0 \mathrm{~Hz}, 1 \mathrm{H}, \mathrm{H}_{19 \mathrm{a}}, \mathrm{NCH}_{2} \mathrm{~N}\right), 5.66(\mathrm{dd}, J=20.0 \mathrm{~Hz}, J$ $\left.=12.0 \mathrm{~Hz}, 1 \mathrm{H}, \mathrm{H}_{23 \mathrm{a}}, \mathrm{NCH}_{2} \mathrm{P}\right), 4.94\left(\mathrm{~d}, J=16.0 \mathrm{~Hz}, 1 \mathrm{H}, \mathrm{H}_{21 \mathrm{a}}\right.$, $\left.\mathrm{NCH}_{2} \mathrm{~N}\right), 4.70-4.64\left(\mathrm{~m}, 2 \mathrm{H}, \mathrm{H}_{17}, \mathrm{NCH}_{2} \mathrm{P},+\mathrm{H}_{21 \mathrm{~b}}, \mathrm{NCH}_{2} \mathrm{~N}\right), 4.15$ $\left(\mathrm{dt}, J=20.0 \mathrm{~Hz}, J=4.0 \mathrm{~Hz}, 1 \mathrm{H}, \mathrm{H}_{17 \mathrm{~b}}, \mathrm{NCH}_{2} \mathrm{P}\right), 4.06(\mathrm{~d}, J=20.0 \mathrm{~Hz}$, $\left.1 \mathrm{H}, \mathrm{H}_{19 \mathrm{~b}}, \mathrm{NCH}_{2} \mathrm{~N}\right), 3.87\left(\mathrm{~s}, 2 \mathrm{H}, \mathrm{H}_{24}, \mathrm{NCH}_{2} \mathrm{P}\right), 3.57(\mathrm{dt}, J=20.0 \mathrm{~Hz}, J$ $\left.=4.0 \mathrm{~Hz}, 1 \mathrm{H}, \mathrm{H}_{23 \mathrm{~b}}, \mathrm{NCH}_{2} \mathrm{P}\right), 2.17\left(\mathrm{~s}, 6 \mathrm{H}, \mathrm{COCH}_{3}\right) . \mathrm{IR}\left(\mathrm{KBr}, \mathrm{cm}^{-1}\right)$ : $3425(\mathrm{C}-\mathrm{H}), 2104(\mathrm{C} \equiv \mathrm{C}), 1640(\mathrm{C}=\mathrm{N})$. ESI-MS $(+): m / z 606.132$ $\left([\mathrm{M}+\mathrm{H}]^{+} ;\right.$calcd $\left.m / z 606.133\right), 1233.233\left([2 \mathrm{M}+\mathrm{Na}]^{+}\right.$; calcd $\mathrm{m} / z$ 1233.241).

Computational Details. All quantum-level calculations were performed with the Amsterdam Density Functional $(A D F)$ program $^{31}$ using the dispersion-corrected density functional ZORA-BLYP-D3$(\mathrm{BJ}) .^{32}$ A previous benchmark study on noncovalent interactions showed that it is essential to incorporate the dispersion correction. ${ }^{33}$ Geometry optimizations of monomers and dimers were obtained with the TZ2P basis set. Geometry optimizations of tetramers were obtained with the TZP basis set, and the bond energies were computed with the TZ2P basis set (single point with the optimized structures). The small frozen-core approximation was applied. Symmetry was applied and is denoted in Table 1 and in the Supporting Information (SI). Solvent effects in $\mathrm{H}_{2} \mathrm{O}$ and DMSO were estimated using the conductor-like screening model (COSMO), ${ }^{34}$ as implemented in the $A D F$ program. ${ }^{35,36}$ According to work by Riley et al., ${ }^{37}$ the dispersion correction does not need to be modified for solvated systems. The bond energy $\Delta E_{\mathrm{bond}}$ of the dimers and tetramers is defined by eqs 1 and 2, respectively:

Table 1. Au-Au Distances ${ }^{a}(\AA)$ and Bond Energies ${ }^{b}$ (kcal/ mol) of the Tetramers of $1 \mathrm{a}, 1 \mathrm{~b}, 2 \mathrm{a}$, and $2 \mathrm{~b}$ in $\mathrm{H}_{2} \mathrm{O}$

\begin{tabular}{|c|c|c|c|}
\hline \multicolumn{4}{|c|}{ Compound 1a } \\
\hline & stacked, $C_{2 h}$ & double dimer, $C_{2 h}$ & chain, $C_{2}$ \\
\hline $\mathrm{Au} 1-\mathrm{Au} 2$ & 5.99 & 3.27 & 4.13 \\
\hline $\mathrm{Au} 2-\mathrm{Au} 3$ & 10.44 & 11.59 & 3.16 \\
\hline $\mathrm{Au} 3-\mathrm{Au} 4$ & 5.99 & 3.27 & 4.13 \\
\hline$\Delta E_{\text {bond }}$ & -56.8 & -41.8 & -65.0 \\
\hline \multicolumn{4}{|c|}{ Compound 2a } \\
\hline & stacked, $C_{2 h}$ & double dimer, $C_{1}$ & chain, $C_{1}$ \\
\hline $\mathrm{Au} 1-\mathrm{Au} 2$ & 5.96 & 3.29 & 3.07 \\
\hline $\mathrm{Au} 2-\mathrm{Au} 3$ & 11.10 & 6.97 & 3.00 \\
\hline $\mathrm{Au} 3-\mathrm{Au} 4$ & 5.96 & 3.28 & 3.10 \\
\hline$\Delta E_{\text {bond }}$ & -57.9 & -42.0 & -67.6 \\
\hline \multicolumn{4}{|c|}{ Compound $\mathbf{1 b}$} \\
\hline & stacked, $C_{i}$ & double dimer, $C_{2}$ & chain, $C_{1}$ \\
\hline $\mathrm{Au} 1-\mathrm{Au} 2$ & 9.73 & 3.26 & 3.18 \\
\hline $\mathrm{Au} 2-\mathrm{Au} 3$ & 6.77 & 11.48 & 3.13 \\
\hline $\mathrm{Au} 3-\mathrm{Au} 4$ & 9.73 & 3.26 & 3.16 \\
\hline$\Delta E_{\text {bond }}$ & -60.2 & -42.5 & -81.4 \\
\hline \multicolumn{4}{|c|}{ Compound $\mathbf{2 b}$} \\
\hline & stacked, $C_{i}$ & double dimer, $C_{i}$ & chain, $C_{1}$ \\
\hline $\mathrm{Au} 1-\mathrm{Au} 2$ & 9.64 & 3.59 & 3.22 \\
\hline $\mathrm{Au} 2-\mathrm{Au} 3$ & 12.35 & 11.46 & 3.07 \\
\hline $\mathrm{Au} 3-\mathrm{Au} 4$ & 9.64 & 3.59 & 3.23 \\
\hline$\Delta E_{\text {bond }}$ & -56.1 & -36.0 & -70.0 \\
\hline
\end{tabular}

${ }^{a}$ Structures of tetramers computed at the ZORA-BLYP-D3(BJ)/TZP level of theory with the COSMO approximation for the solvent $\left(\mathrm{H}_{2} \mathrm{O}\right) .{ }^{b}$ Bond energies computed at the ZORA-BLYP-D3(BJ)/TZ2P level of theory with the COSMO approximation for the solvent $\left(\mathrm{H}_{2} \mathrm{O}\right)$. 
Scheme 1. Synthesis of $\left[\mathrm{Au}\left(\mathrm{C} \equiv \mathrm{CC}_{15} \mathrm{H}_{10} \mathrm{~N}_{3}\right)\left(\mathrm{PR}_{3}\right)\right]\left[\mathrm{PR}_{3}=\mathrm{PTA}(1 \mathrm{a})\right.$ and DAPTA (1b) $]$ Complexes

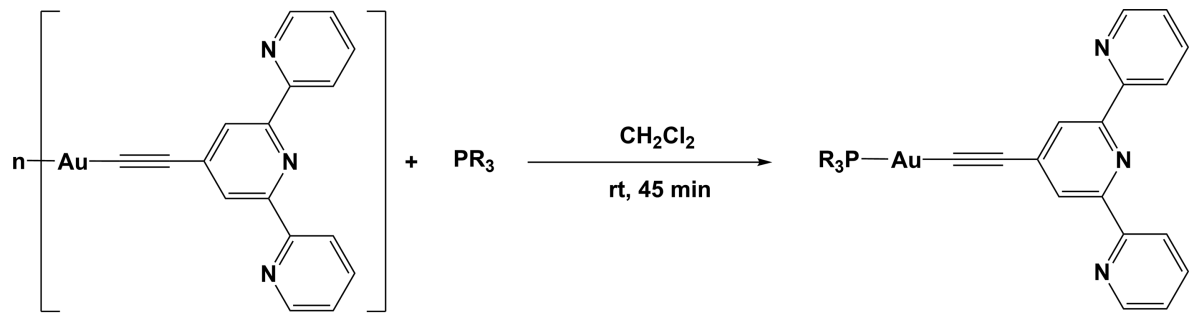

$\mathrm{PR}_{3}=$ PTA (1a); DAPTA (1b)

Scheme 2. Synthesis of $\left[\mathrm{Au}\left(\mathrm{C} \equiv \mathrm{CC}_{10} \mathrm{H}_{7} \mathrm{~N}_{2}\right)\left(\mathrm{PR}_{3}\right)\right]\left[\mathrm{PR}_{3}=\mathrm{PTA}(2 \mathrm{a})\right.$ and DAPTA (2b) $]$ Complexes

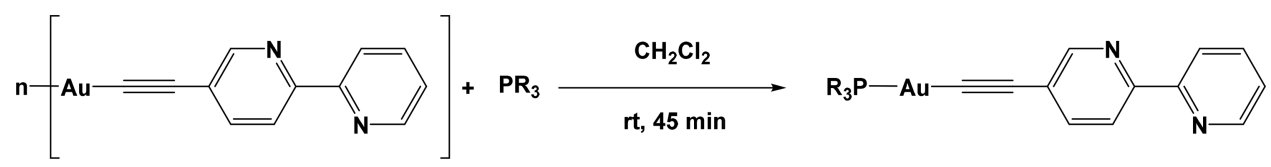

$\mathrm{PR}_{3}=\mathrm{PTA}(\mathbf{2 a}) ;$ DAPTA (2b)

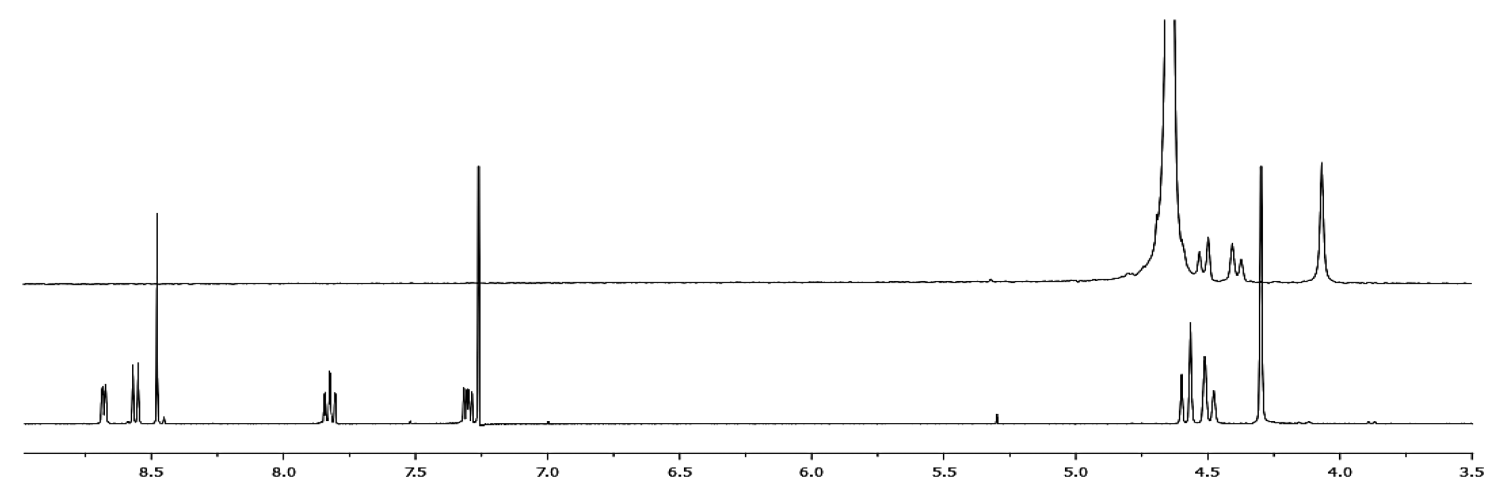

Figure 1. ${ }^{1} \mathrm{H}$ NMR spectra (400 MHz) of compound $1 \mathrm{a}$ in $\mathrm{D}_{2} \mathrm{O}$ (top) and $\mathrm{CDCl}_{3}$ (bottom) at $5 \times 10^{-4} \mathrm{M}$ concentration and $298 \mathrm{~K}$.

$$
\begin{aligned}
& \Delta E_{\text {bond }}=E_{\text {dimer }}-2 E_{\text {monomer }} \\
& \Delta E_{\text {bond }}=E_{\text {tetramer }}-4 E_{\text {monomer }}
\end{aligned}
$$

where $E_{\text {tetramer }}$ is the energy of the optimized tetramer, $E_{\text {dimer }}$ is the energy of the optimized dimer, and $E_{\text {monomer }}$ is the energy of one of the four different optimized monomers used.

\section{RESULTS AND DISCUSSION}

Synthesis and Characterization. Complexes 1 and 2 were obtained by the same methodology as that previously described in the literature for $\left[\mathrm{Au}\left(\mathrm{C} \equiv \mathrm{CC}_{5} \mathrm{H}_{4} \mathrm{~N}\right)(\mathrm{PTA})\right]^{8}$ and $[\mathrm{Au}(\mathrm{C} \equiv$ $\left.\mathrm{CC}_{5} \mathrm{H}_{4} \mathrm{~N}\right)(\mathrm{DAPTA})$. $^{9} \mathrm{~A} \mathrm{CH}_{2} \mathrm{Cl}_{2}$ suspension of the previously synthesized $\left[\mathrm{Au}\left(\mathrm{C} \equiv \mathrm{CC}_{15} \mathrm{H}_{10} \mathrm{~N}_{3}\right)\right]_{n}$ (for $\mathbf{1 a}$ and $\mathbf{1 b}$ ) or $\left[\mathrm{Au}\left(\mathrm{C} \equiv \mathrm{CC}_{10} \mathrm{H}_{7} \mathrm{~N}_{2}\right)\right]_{n}$ (for $\mathbf{2 a}$ and $\mathbf{2 b}$ ) polymer was stirred with the phosphine PTA or DAPTA in a 1:1 ratio (Schemes 1 and 2). The reaction was maintained under stirring at room temperature for $45 \mathrm{~min}$. Coordination of these phosphines (PTA and DAPTA) immediately gave yellow solutions that, after concentration and the addition of $n$-hexane, yielded the corresponding complexes quantitatively.

Characterization of complexes 1 and 2 by ${ }^{1} \mathrm{H}$ and ${ }^{31} \mathrm{P}$ NMR and IR spectroscopies and mass spectrometry verified the successful formation of these products. Mass spectrometry measurements were able to detect the corresponding molecular peaks of the protonated species in all cases (see the SI). ${ }^{1} \mathrm{H}$ NMR spectra of the complexes recorded in $\mathrm{CDCl}_{3}$ show the characteristic protons of the terpyridine ${ }^{38-41}(\mathbf{1 a}$ and $\mathbf{1 b})$ and of the bipyridine ${ }^{20,42}(\mathbf{2} \mathbf{a}$ and $\mathbf{2 b})$, together with the characteristic patterns of the phosphines PTA (1a and $\mathbf{2 a}$ ) or DAPTA (1 $\mathbf{b}$ and $\mathbf{2} \mathbf{b}){ }^{8-11}$ (see the SI). ${ }^{31} \mathrm{P}\left\{{ }^{1} \mathrm{H}\right\}$ NMR spectra carried out in $\mathrm{CDCl}_{3}$ typically show one signal between -10 and $-50 \mathrm{ppm}$, with a $50 \mathrm{ppm}$ (for PTA derivatives) or a 30 ppm (for DAPTA derivatives) downfield shift in comparison with the free phosphines. The corresponding $\mathrm{C} \equiv \mathrm{C}$ and $\mathrm{C}=\mathrm{N}$ vibrations of the chromophoric units were also observed in the IR spectra in all cases.

Aggregation in Water and Water/DMSO Mixtures. As was previously found for neutral gold(I) alkynyl complexes, ${ }^{8-10}$ aged solutions of $\mathbf{1 a}, \mathbf{1} \mathbf{b}, \mathbf{2} \mathbf{a}$, and $\mathbf{2} \mathbf{b}$ in $\mathrm{H}_{2} \mathrm{O}$ give origin to the formation of luminescent fibers (Figure S9), apparently originating from the merging of smaller aggregates ${ }^{10}$ (see the SAXS and DLS discussion below). The fibers are not observed from DMSO and chloroform solutions in the same time scale.

In $\mathrm{D}_{2} \mathrm{O}$, terpyridyl and bipyridyl protons are not observed in ${ }^{1} \mathrm{H}$ NMR, even under highly diluted conditions (Figure 1), while the phosphine protons are clearly seen, even if they are slightly broader than those in $\mathrm{CDCl}_{3}$. The absence of the terpyridyl and bipyridyl proton signals is an expected result from aggregation because of the slower mobility of the aggregates. What is unexpected is that the phosphine protons are still detected in the aggregates because the restriction in mobility should apply to both parts of the molecule.

In order to obtain deeper knowledge of the self-assembling process at the molecular level, we performed a series of NMR spectroscopy studies in $\mathrm{D}_{2} \mathrm{O} / \mathrm{DMSO}-d_{6}$ mixtures because the good miscibility of both solvents and the complete solubiliza- 


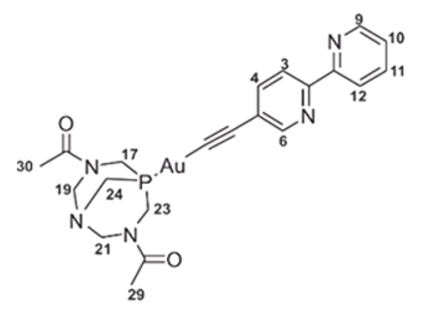

b

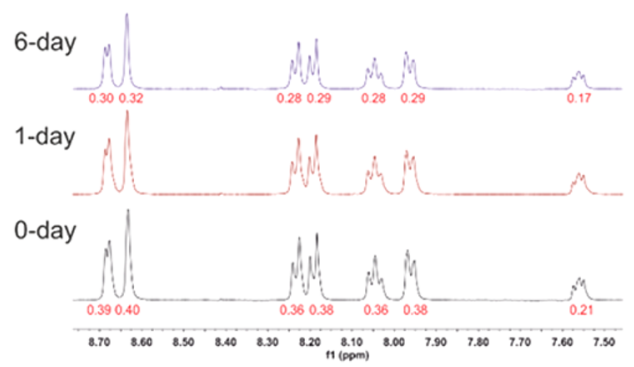

C

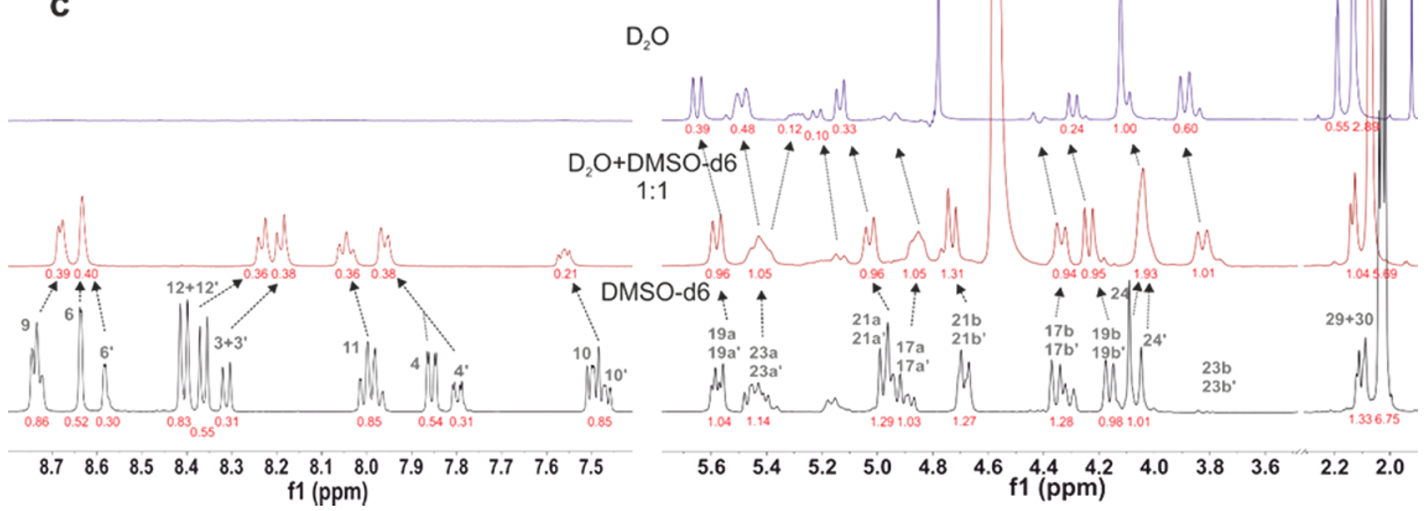

Figure 2. (a) Chemical structure of $\mathbf{2 b}$ with labeling numbers used in the NMR assignment. (b) ${ }^{1} \mathrm{H}$ NMR spectra (aromatic region) of $1 \mathrm{mM} 2 \mathbf{b}$ at different times after dissolution in $\mathrm{D}_{2} \mathrm{O} / \mathrm{DMSO}-d_{6}(1: 1)$. (c) ${ }^{1} \mathrm{H}$ NMR spectra of $1 \mathrm{mM} \mathbf{2 b}$ in different solvent conditions. The experiments were acquired at $500 \mathrm{MHz}$ and $298 \mathrm{~K}$, with a relaxation delay of $20 \mathrm{~s}$. Below the peaks, the numbers in red are the normalized peak area values (integral).

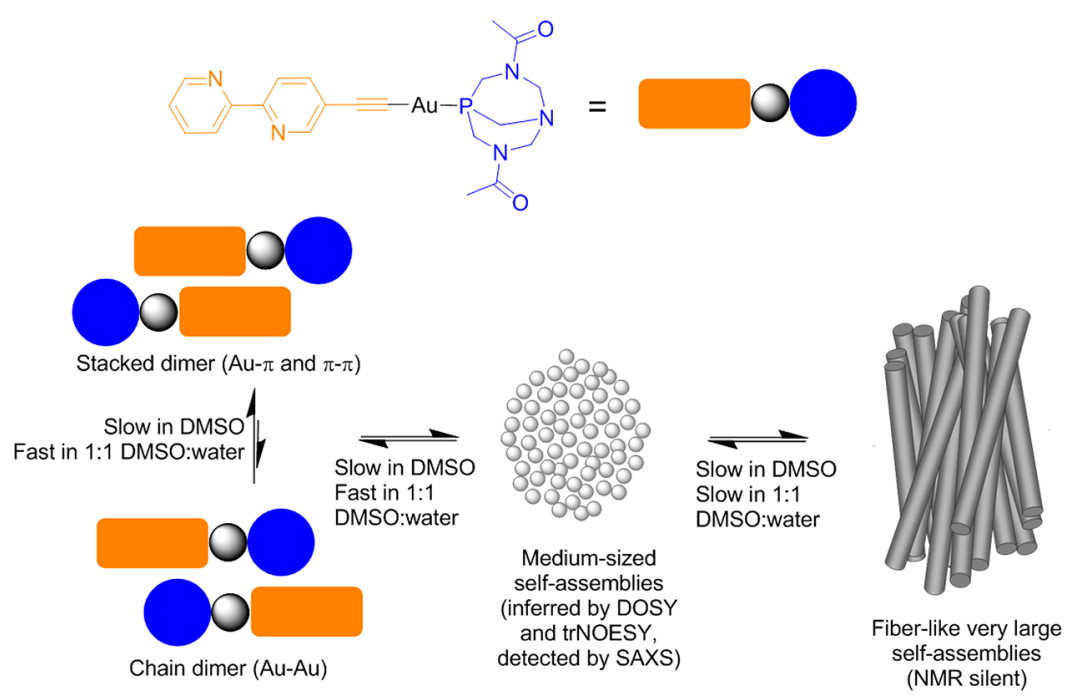

Figure 3. Schematic representation of the possible aggregates observed in solution.

tion of the molecules in DMSO- $d_{6}$ (Figure S10), having behavior comparable to that previously observed in $\mathrm{CDCl}_{3}$. We must point out that the very large aggregates are invisible in conventional solution NMR experiments because of the large line broadening produced by the very efficient transverse relaxation in large molecular entities. The ${ }^{1} \mathrm{H}$ NMR spectrum of $\mathbf{2 b}$ in pure DMSO- $d_{6}$ showed well-resolved signals, implying the major presence of discrete species (Figures 2c, black trace, and S9) suitably assigned by $2 \mathrm{D}{ }^{1} \mathrm{H}-{ }^{13} \mathrm{C}$ HSQC and $\mathrm{HMBC}$ experiments (Figures S11 and S12). However, two sets of signals were clearly observed in a 63:37 proportion, suggesting the presence of two species in solution (with notation $\mathrm{H}$ and $\mathrm{H}^{\prime}$ in Figure 2). The NOESY spectrum of this sample showed a cross-peak between the $\mathrm{H}_{6}{ }^{\prime}$ signal and the methyl signal of the acetyl of the DAPTA moiety, suggesting that the minor species should locate the bipyridyl and DAPTA moieties in relatively close proximity (Figure S13).

The DOSY experiment (Figures S14 and S15) rendered an apparent molecular size corresponding to a dimer structure for the two observed species (Table S2; hydrodynamic radii of 7.3 and $8.6 \AA$ for the minor and major species, respectively). Accordingly, we assigned the minor species to the chain dimer and the major one to the stacked dimer (Figure 3). Very interestingly, the measured longitudinal and transverse relaxation times (Table S1) are unexpectedly long for discrete organic molecules in solution. Moreover, the magnetic relaxation of the signals from the bipyridyl moiety showed to be less efficient than the relaxation of the DAPTA moiety. This 
could be due to some rigidity of the bipyridyl group, although no definitive conclusions could be drawn due to the implication of the DAPTA moiety in a cis/trans dynamic process of the corresponding tertiary amide groups. Actually, the molecular system is implicated in the different exchange processes that occurred at very different time scales, as observed by the EXSY peaks in the NOESY experiments (Figure S13).

Thus, the amide cis/trans isomerization of DAPTA is slow in the chemical shift NMR time scale and can be observed by exchange cross-peaks in the NOESY experiments at $250 \mathrm{~ms}$. Additionally, the exchange between the two dimeric species (chain/stacked; Figure 3) is slow in both the NMR chemical shift and NOESY time scales (exchange slower than $0.5 \mathrm{~s}$ ). The complexity of the systems is even higher when looking at the integrals of the ${ }^{1} \mathrm{H}$ NMR signals. The ${ }^{1} \mathrm{H}$ NMR spectrum acquired at quantitative conditions (with a relaxation delay of $20 \mathrm{~s}$ ) showed that the intensities of the bipyridine signals are lower than the ones for DAPTA, once again suggesting that the bipyridyl ring is closely implicated in the self-assembling process. Besides, a comparison of the integrals of the observed NMR signals with that of an internal standard showed that about $10 \%$ of the molecule remains undetected in solution NMR, suggesting the presence of large aggregates even in pure DMSO- $d_{6}$. The apparent lower motion of the bipyridyl rings is also observed in the negative NOE cross-peaks, which implies a longer apparent tumbling time of this part of the molecule.

To study the effect of $\mathrm{H}_{2} \mathrm{O}$ on the self-assembly, we performed a titration of the sample initially prepared in DMSO$d_{6}$ with increasing amounts of $\mathrm{D}_{2} \mathrm{O}$ (Figure S16). The increase of the polarity of the medium produced changes in the bipyridyl proton signals, which is in agreement with the previously reported behavior. ${ }^{43}$ All the signals broadened, and the protons corresponding to the two dimeric species started to approach their chemical shifts (without an apparent variation in the proportion of the species). This suggests that the presence of $\mathrm{H}_{2} \mathrm{O}$ accelerates the exchange between the two dimeric species. The DOSY experiment at $20 \% \mathrm{D}_{2} \mathrm{O}$ in DMSO- $d_{6}$ showed the clear presence of two dimeric species with apparent sizes similar to that observed in pure DMSO (Table S2 and Figure S17). However, the ${ }^{1} \mathrm{H}$ NMR signals coalesce at a $1: 1$ DMSO- $d_{6} / \mathrm{D}_{2} \mathrm{O}$ mixture, in which a single set of signals was observed for the bipyridyl moiety (Figure $2 c$, red trace). The NOESY spectrum of this sample showed peaks that are compatible with the two dimeric structures, implying that a fast exchange must occur between the chain and stacked species in this solvent mixture (Figure S18). This is also supported by the negative sign of the NOESY peaks, implying an apparent larger size of the species in solution rendering transferred NOESY effects between the dimeric species and larger aggregates. The integrals of the protons in the $1 \mathrm{D}{ }^{1} \mathrm{H}$ NMR spectrum suggested a higher proportion of invisible aggregates, while the DOSY experiments (Figure S19) rendered values compatible with the presence of dimeric species and in equilibrium with larger aggregates (hydrodynamic radii of 7.8 and $15.0 \AA$ for different signals of the spectrum; Table S2). Moreover, acquisition of the ${ }^{1} \mathrm{H}$ NMR spectrum after longer preparation times showed a decrease in the intensity signals with time (Figure $2 b$ ), implying the slow formation of very large self-assemblies ( 6 days).

Finally, the ${ }^{1} \mathrm{H}$ NMR spectrum of a sample prepared in pure $\mathrm{D}_{2} \mathrm{O}$ showed a further decrease in the intensity of the protons of DAPTA and the complete disappearance of the signals from the bipyridyl moiety (Figure 2c, blue trace). The NOESY spectrum of this sample (Figure S20) showed spin-diffusion effects in agreement with the formation of very large aggregates in solution where the bipyridine would be less accessible to the solvent, leading to a large broadening up to undetectable signals. A faster dynamic and solvent exposure of the DAPTA fragments allowed the detection of their NMR signals. The same behavior was observed for complex 2a in pure DMSO- $d_{6}$ and a 1:1 DMSO- $d_{6} / \mathrm{D}_{2} \mathrm{O}$ mixture (Figures S21-S26).

${ }^{31} \mathrm{P}$ NMR experiments recorded in different DMSO- $d_{6} / \mathrm{D}_{2} \mathrm{O}$ proportions are in agreement with these data. A broad signal is observed in pure DMSO- $d_{6}$, implying the existence of different conformations in slow equilibrium. Moreover, the increase of the amounts of $\mathrm{D}_{2} \mathrm{O}$ shifts to a sharp and clearly defined downfield peak, as expected when the equilibrium between the chain and stacked conformations becomes faster in $\mathrm{D}_{2} \mathrm{O}$ (Figures S27 and S28).

Considering all of these NMR results, a putative selfassembling mechanism for gold(I) complexes $\mathbf{2} \mathbf{a}$ and $\mathbf{2} \mathbf{b}$ is proposed in Figure 3.

The aggregation has a visible impact on the optical properties of the solutions in both the absorbed and emitted light. With an increase in the $\mathrm{H}_{2} \mathrm{O}$ content, there is a clear change of the absorption toward the visible region, displayed by the yellowing of the solutions, and at the same time, the strong blue emission observed in DMSO is quenched at increasing amounts of $\mathrm{H}_{2} \mathrm{O}$ and replaced by a red emission (Figures 4 and S29).

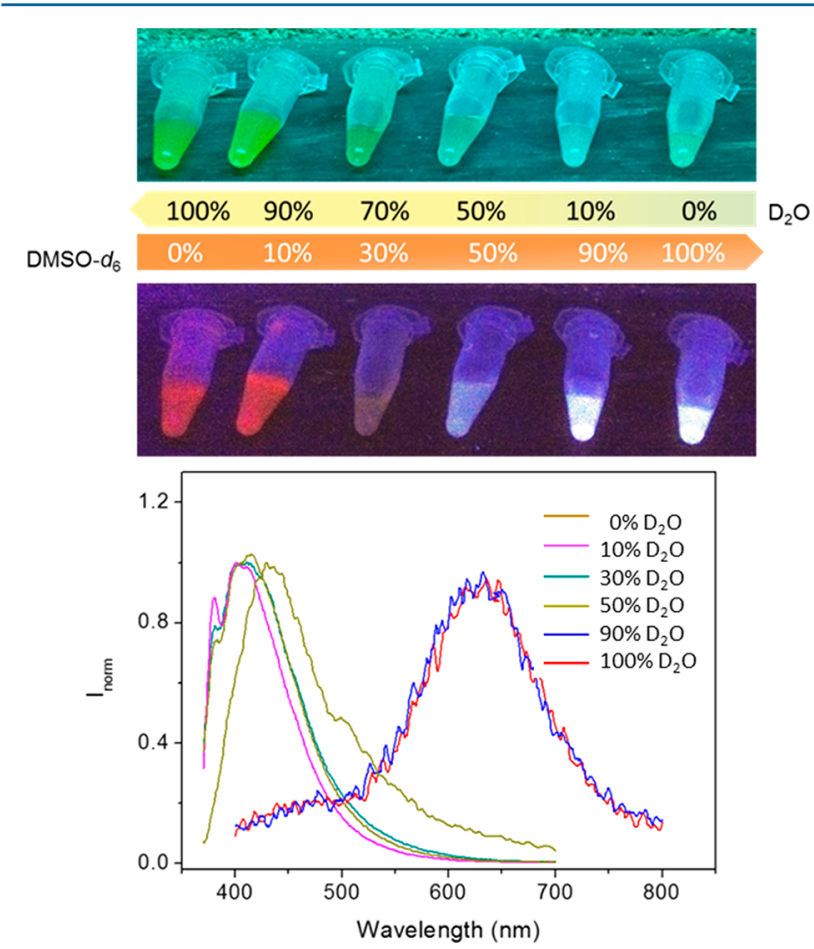

Figure 4. (top) Variation of the color of $1 \times 10^{-4} \mathrm{M} \mathrm{D}_{2} \mathrm{O} / \mathrm{DMSO}-d_{6}$ solutions of $\mathbf{2 b}$ under visible and UV light. (bottom) Normalized emission of $\mathbf{2} \mathbf{b}$ at different compositions of DMSO- $d_{6} / \mathrm{D}_{2} \mathrm{O}\left(\lambda_{\text {exc }}=360\right.$ $\mathrm{nm})$.

The lower-energy band at ca. $630 \mathrm{~nm}$ is assigned to the aggregates, where the presence of excimers due to $\pi-\pi$ or $\mathrm{Au}-\pi$ stacking can contribute to both the broad shape and red shift of the band. ${ }^{11}$ These interactions seem to be more favored in $\mathrm{H}_{2} \mathrm{O}$, in agreement with theoretical calculations (see below). The higher emission band at $430 \mathrm{~nm}$ is assigned to the singlet metal-to-ligand charge-transfer $\left({ }^{1} \mathrm{MLCT}\right) /$ singlet ligand-to- 


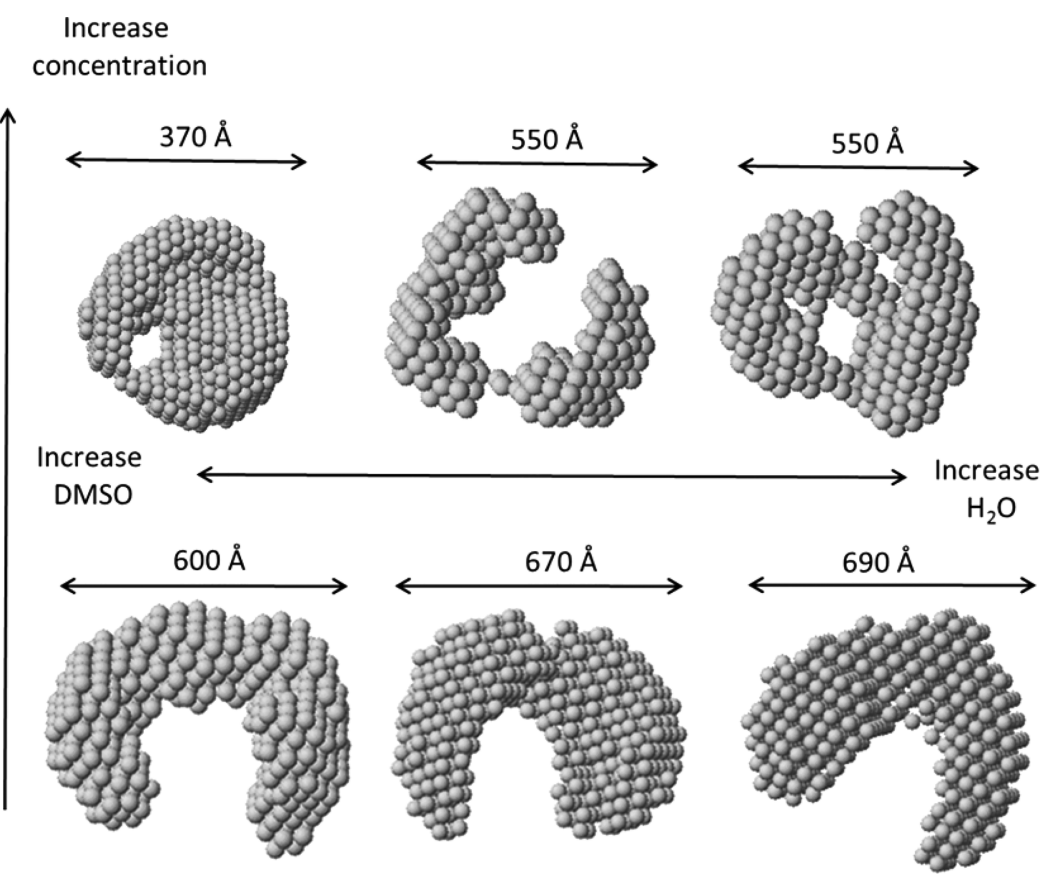

Figure 5. DAMMIN low-resolution structures reconstructed from SAXS patterns for $1 \times 10^{-4} \mathrm{M}$ (top) and $1 \times 10^{-5} \mathrm{M}$ (bottom) solutions of $2 \mathrm{a}$ in DMSO (left), 1:1 $\mathrm{H}_{2} \mathrm{O} / \mathrm{DMSO}$ (center), and 3:1 $\mathrm{H}_{2} \mathrm{O} / \mathrm{DMSO}$ (right).

$1 \mathrm{a}$

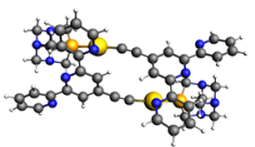

$1 \mathrm{~b}$

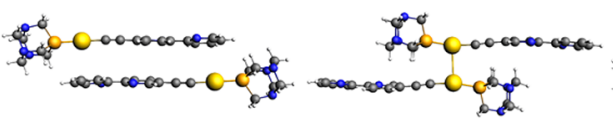

2a

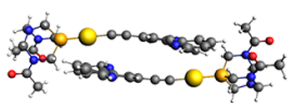

$2 b$
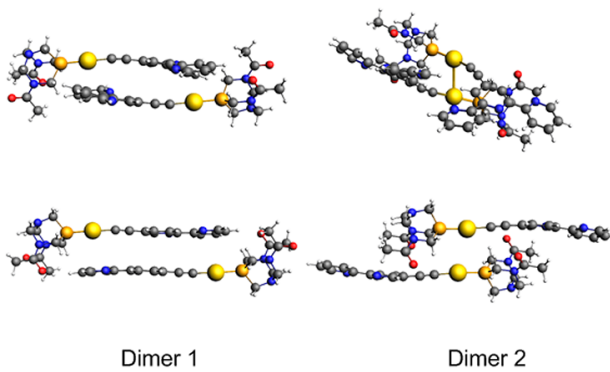
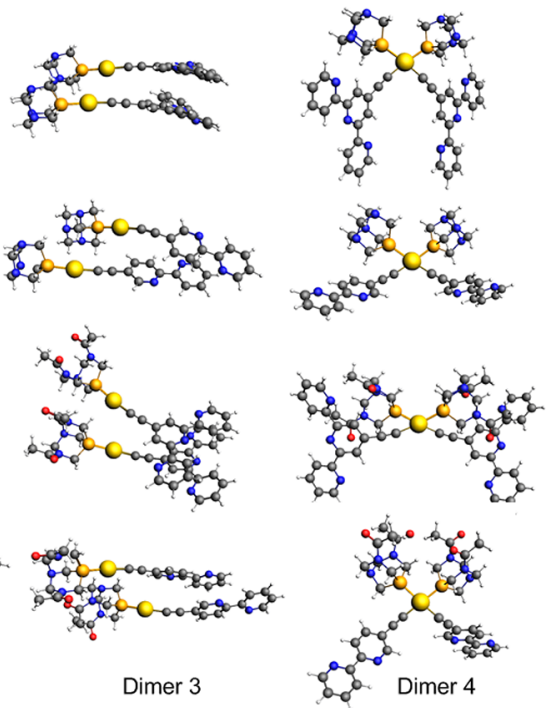

Figure 6. Structures of the computed dimers.

ligand charge-transfer $\left({ }^{1}\right.$ LLCT) transition, being more favored in DMSO, because of the presence of a chain conformation, which allows free movement of the phosphane and polypyridine moieties of the compounds in the aggregates (mainly aurophilic interactions).

SAXS measurements were performed for $1 \times 10^{-5}$ and $1 \times$ $10^{-4} \mathrm{M}$ solutions of the compounds in different $\mathrm{H}_{2} \mathrm{O} / \mathrm{DMSO}$ proportions. The low-resolution structures were reconstructed $\mathrm{ab}$ initio from the scattering patterns using the DAMMIN program $^{30}$ and are shown in Figures 5 and S30-S32 for two concentrations and two solvent compositions.

The observation is that, in all mixtures, the large aggregates show comparable dimensions at the same concentration, independent of the solvent composition and, in general, a slight increase in the sizes of the aggregates is shown with an increase in the $\mathrm{H}_{2} \mathrm{O}$ concentration. There is no significant difference in the sizes between the terpyridyl and bipyridyl derivatives (Figures 5 and S30-S32). This result suggests that aggregates exist in the different $\mathrm{H}_{2} \mathrm{O} / \mathrm{DMSO}$ mixtures of the solvents, and the differences observed may arise from internal reordering of the aggregates (chain/stacked aggregates detected by NMR and luminescence). Additionally, the temperature does not significantly affect the size or the shape of the resulting structures (Figures S33-S36).

DLS measurements were in agreement with the presence of aggregates in DMSO at $1 \times 10^{-4} \mathrm{M}$ concentration. The presence of ca. $100 \mathrm{~nm}$ size supramolecular structures is observed in all cases (Figures S37-S40). As expected, the sizes of the aggregates obtained by DLS and SAXS are much larger than the hydrodynamic radii previously calculated by NMR 

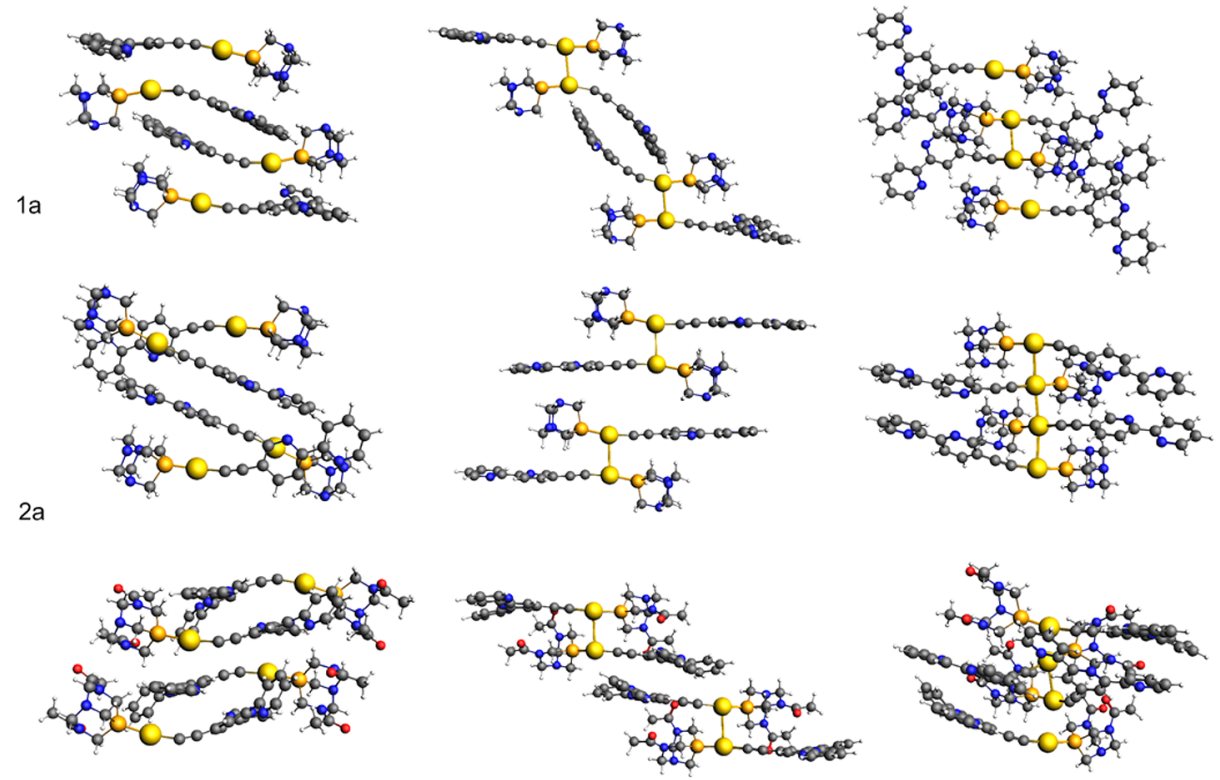

$1 \mathrm{~b}$
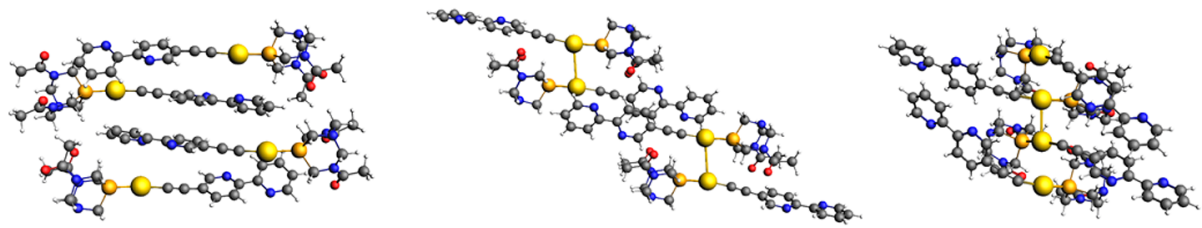

$2 b$

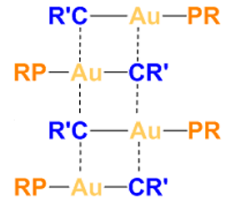

Stacked

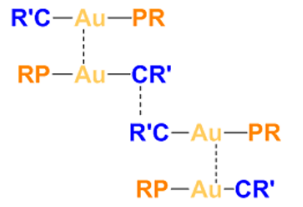

Double Dimer

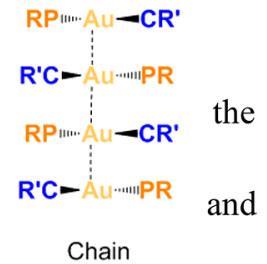

Figure 7. Structures of the computed tetramers and schematic representation.

DOSY experiments (see above). SAXS/DLS and NMR techniques are complementary toward the detected assembly size: because of the slow tumbling of larger macromolecules in solution leading to faster relaxation of transverse magnetization, only the soluble dimers and small aggregates in equilibria with the larger assemblies (detected by SAXS/DLS) are observed by NMR (the larger structures are "invisible" in solution NMR).

Computational Study of the Aggregation Modes. We have computationally analyzed the structures of $\mathbf{1 a}, \mathbf{1 b}, \mathbf{2} \mathbf{a}$, and 2b (Figure S41) and their autoassociation properties to form different dimers and tetramers (as a model for larger aggregates).

We have analyzed different dimerization and tetramerization possibilities for each of the monomers in Figure S41, involving different arrangements of ligand-ligand, $\mathrm{Au}-\mathrm{Au}$, and ligand$\mathrm{Au}$ interactions (Figures 6 and 7).

An important difference between the tetramers calculated is that, in the stacked conformation, the main contribution arises from $\mathrm{Au}-\pi$ interactions, in the double dimer, there are contributions from $\mathrm{Au}-\mathrm{Au}$ and $\pi-\pi$ interactions, while in the chain conformation, the main contribution is a continuous chain of $\mathrm{Au}-\mathrm{Au}$ interactions that grows with the aggregate size.
The $\mathrm{Au}-\mathrm{Au}$ distances between successive monomeric units in the tetramers and the bond energies are summarized in Table 1.

Note that, with no exception, there is a nonnegligible stabilization of the chain conformation in the tetramers. The same is not observed for the bond energies of the dimers, collected in Table 2. For the dimers, the conformations with shorter $\mathrm{Au}-\mathrm{Au}$ distances (dimers 2 and 4, $\mathrm{Au} \cdots \mathrm{Au}$ interactions) are not more stable than the conformations with favored ligand-ligand interactions, either in head-to-tail (dimer $1 ; \pi \cdots$ $\mathrm{Au}$ interaction) or head-to-head (dimer $3 ; \pi-\pi$ interaction) conformations (Figure 6). That is, the formation of the dimers in $\mathrm{H}_{2} \mathrm{O}$ in the stacked conformation is more favored according to these calculations (in agreement with the luminescence data), while the predicted stability of the larger structures does not seem to be so straightforward because entropic factors (not considered here) should be more important in the presence of $\pi \cdots \mathrm{Au}$ interactions.

Another distinct aspect of the aggregation modes is related to the impact of the aggregates on the observables from either NMR, SAXS, and optical spectroscopies. For all of the tetramers, the favored aggregation modes are either stacked or chain aggregation. On the contrary, while chain aggregation minimizes hydrophobic interactions of the chromophoric unit 
Table 2. Au-Au Distances $(\AA)$ and Bond Energies ${ }^{a}$ (kcal/ mol) of the Tetramers of $1 a, 1 b, 2 a$, and $2 b$ in $\mathrm{H}_{2} \mathrm{O}$

\begin{tabular}{|c|c|c|c|c|}
\hline & dimer 1 & dimer 2 & dimer 3 & dimer 4 \\
\hline \multicolumn{5}{|c|}{ Compound 1a } \\
\hline $\mathrm{Au}-\mathrm{Au}$ distance & 6.20 & 3.39 & 4.72 & 3.22 \\
\hline$\Delta E_{\text {bond }}$ & -21.1 & -11.1 & -20.2 & -18.5 \\
\hline \multicolumn{5}{|c|}{ Compound 2a } \\
\hline $\mathrm{Au}-\mathrm{Au}$ distance & 11.67 & 3.24 & 5.33 & 3.34 \\
\hline$\Delta E_{\text {bond }}$ & -21.2 & -14.5 & -22.2 & -15.5 \\
\hline \multicolumn{5}{|c|}{ Compound $\mathbf{1 b}$} \\
\hline $\mathrm{Au}-\mathrm{Au}$ distance & 9.50 & $3.30^{b}$ & 4.41 & 3.17 \\
\hline$\Delta E_{\text {bond }}$ & -25.0 & $-14.7^{b}$ & -18.7 & -11.7 \\
\hline \multicolumn{5}{|c|}{ Compound $\mathbf{2 b}$} \\
\hline $\mathrm{Au}-\mathrm{Au}$ distance & 11.42 & 3.86 & 5.41 & 3.25 \\
\hline$\Delta E_{\text {bond }}$ & -20.0 & -8.6 & -22.3 & -13.0 \\
\hline
\end{tabular}

${ }^{a}$ Bond energies of the dimers computed at the ZORA-BLYP-D3(BJ)/ TZP level of theory with the COSMO approximation for the solvent $\left(\mathrm{H}_{2} \mathrm{O}\right) .{ }^{b}$ The structure of dimer 2 of $\mathbf{1 b}$ is close to the structure of dimer 4.

and maximizes exposure to the solvent, the stack aggregation maximizes the hydrophobic $\mathrm{Au} \cdots \pi$ interaction, pulling the chromophoric unit toward the core of the aggregate while allowing the phosphine unit full exposure to the solvent. The stack aggregation thus is compatible with the excitonic interaction displayed in both the absorbed (yellowing) and emitted (quenching and red shift) light and can be the major species observed with an increase in the amount of $\mathrm{D}_{2} \mathrm{O}$ in luminescence studies. By the same argument, chain aggregation is more compatible with the optical spectroscopy data obtained in DMSO, where both aromatic and phosphine protons are exposed to the solvent and the chromophore absorption in the $\mathrm{UV}$, together with the blue emission, is recovered. At the same time, a second species (chain conformers) is detected in ${ }^{1} \mathrm{H}$ NMR spectra recorded in pure DMSO- $d_{6}$. Calculations performed in DMSO support this fact (Table S3). It can be seen that the contribution of the chain conformation becomes more important in this solvent, mainly in the bipyridyl complexes. In fact, the charge-transfer (CT) contribution observed in the case of the $\mathrm{Au} \cdots \mathrm{Au}$ interactions ${ }^{44}$ increases with the number of $\mathrm{Au}$ atoms involved in the chain and while a single $\mathrm{Au} \cdots \mathrm{Au}$ bond is on the same order of magnitude as other interactions ( $\mathrm{Au} \cdots \pi$ and $\pi \cdots \pi$ stacking). With growth of the number of $\mathrm{Au}$ atoms, these interactions become more important in stabilization of the aggregates.

We cannot forget that theoretical calculations take into consideration the bonding energy, while some entropic aspects, like hydrophobic interactions (expected to be more important for terpyridyl complexes), have a direct impact on the aggregation.

Reversible Aggregation/Dissaggregation Processes. The presence of $\mathrm{N}$-donor atoms in the chemical structure of the complexes makes these systems ideal candidates for cation coordination. The main important point in this work is that the coordination of cations may have a direct influence on the resulting aggregates being able to externally modulate the formation/dissolution of the supramolecular structures. The initial solutions display the typical $\pi-\pi^{*}\left(\mathrm{C} \equiv \mathrm{CC}_{15} \mathrm{H}_{10} \mathrm{~N}_{3}\right.$; for $\mathbf{1 a}$ and $\mathbf{1 b})$ or $\pi-\pi^{*}\left(\mathrm{C} \equiv \mathrm{CC}_{10} \mathrm{H}_{7} \mathrm{~N}_{2} ;\right.$ for $\mathbf{2 a}$ and $\left.\mathbf{2 b}\right)$ absorption transitions of chromophores between 310 and 360 $\mathrm{nm} .^{20,45,46}$ Additionally, a band at higher energy (ca. $280 \mathrm{~nm}$ ) due to the intraligand absorption of the phosphine is also recorded, and another band at lower energy and with very low intensity between 360 and $400 \mathrm{~nm}$ is also present, which is assigned to a $\sigma_{\mathrm{Au}-\mathrm{Au}}^{*} \rightarrow \pi^{*}$ transition, in agreement with previous data based on theoretical and thermodynamic calculations $^{44,47}$ (Figure S42). In order to check the ability of the complexes to coordinate metal cations, aqueous solutions $\left(1 \times 10^{-4} \mathrm{M}\right)$ of $\mathbf{1} \mathbf{a}-\mathbf{b}, \mathbf{2} \mathbf{a}-\mathbf{b}$ were titrated with $\mathrm{Zn}^{2+}$, chosen as a divalent ion that can coordinate to $\mathrm{N}$ atoms. Absorption and emission variations in the presence of increasing amounts of $\mathrm{Zn}^{2+}$ were detected, and they are displayed in Figures 8 and S43-S45.

An interesting feature is observed with an increase in the amount of $\mathrm{Zn}^{2+}$. The broad intraligand absorption band turns to some vibronic resolution profile with higher absorption. Meanwhile, the red emission band disappears, and a blue fluorescence, previously assigned to ${ }^{1} \mathrm{MLCT}$, rises for DMSO solutions. Emission bands resulting from $\mathrm{Zn}^{2+}$ coordination present some vibronic resolution, typical of nonaggregated chromophores. Additionally, the resulting blue emission is much higher in intensity than the red aggregated emission, as observed in the $\mathrm{H}_{2} \mathrm{O} / \mathrm{DMSO}$ solutions of the compounds.

The plot of the emission variations against the $\mathrm{Zn}^{2+}$ concentration displays a change in the slope at ca. 0.3 equiv (Figure 8, right inset), which is an indication of 1:3 (divalent cation/gold complex) coordination (Figure S46).
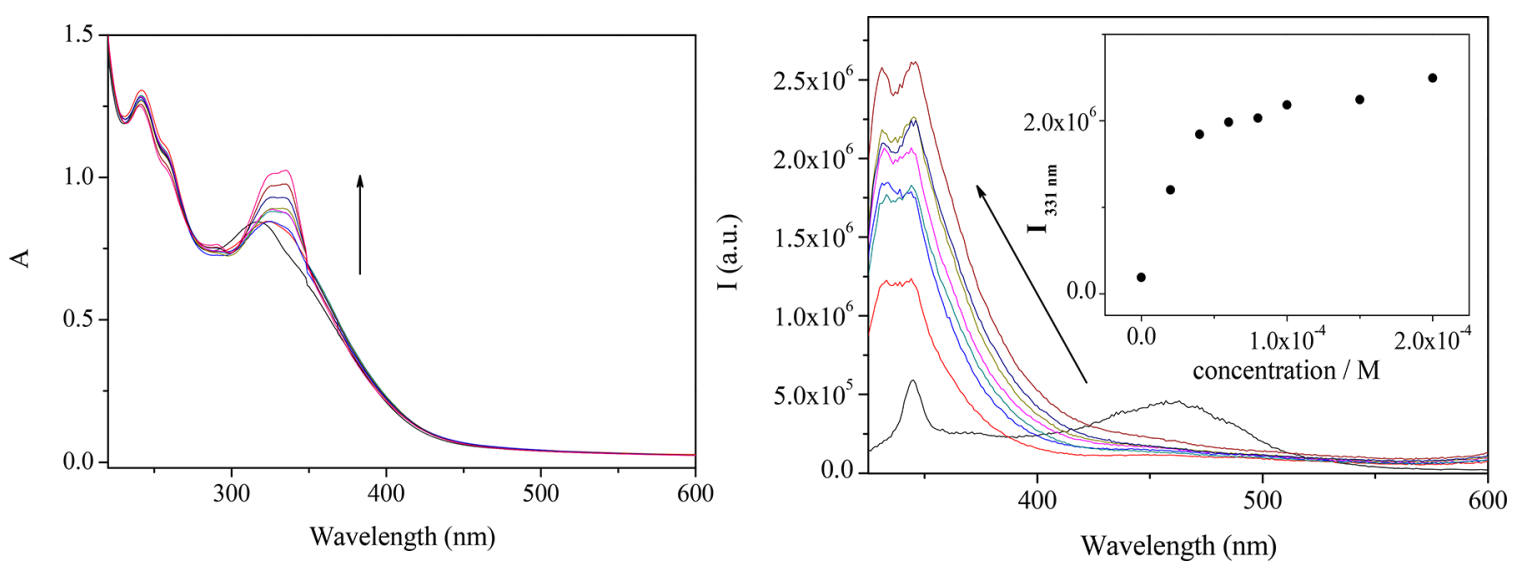

Figure 8. Absorption (left) and emission (right) spectra of a $1 \times 10^{-4} \mathrm{M}$ aqueous solution of $2 \mathrm{a}$ in the presence of increasing amounts of $\mathrm{Zn}^{2+}$. 


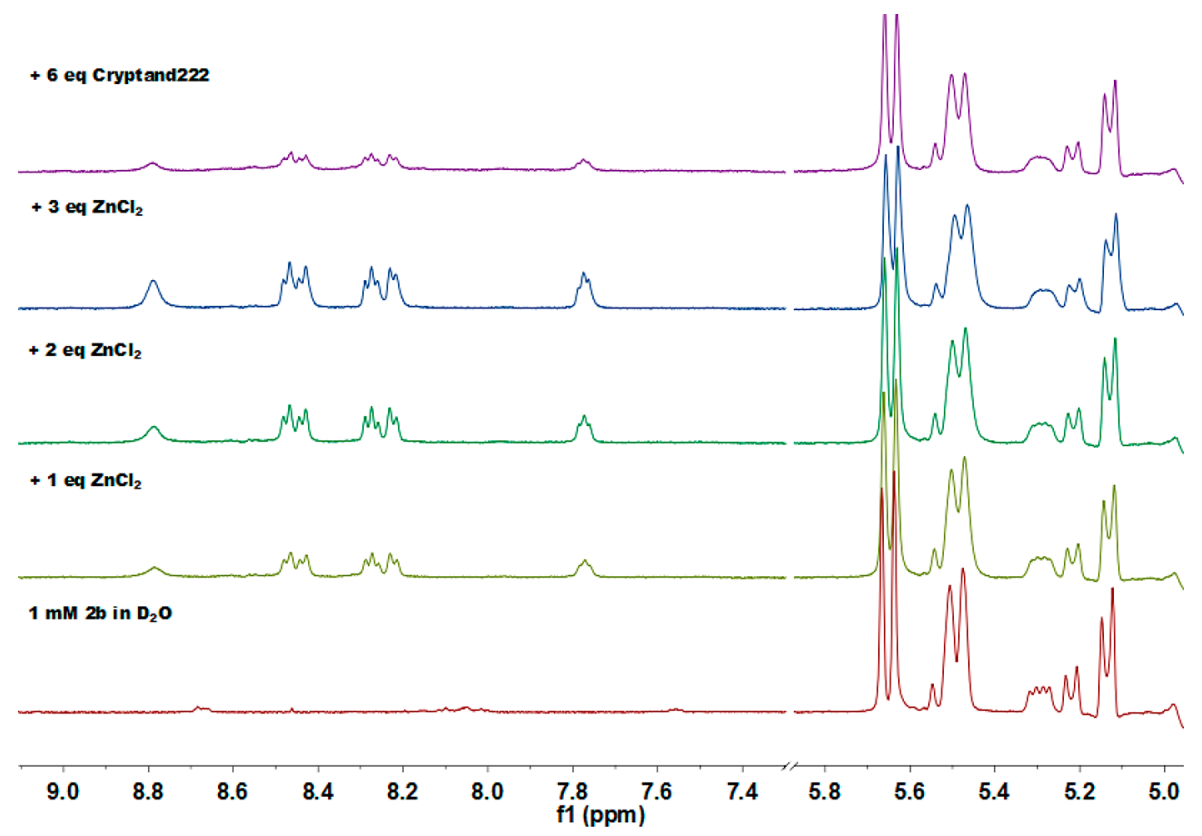

Figure 9. ${ }^{1} \mathrm{H}$ NMR spectra of $0.9 \mathrm{mM} 2 \mathbf{b}$ in $\mathrm{D}_{2} \mathrm{O}$ and with increasing amounts of metal $\left(1,2\right.$, or 3 equiv of $\left.\mathrm{ZnCl}_{2}\right)$ and after the addition of 6 equiv of cryptand to the sample with 3 equiv of $\mathrm{Zn}^{2+}$.
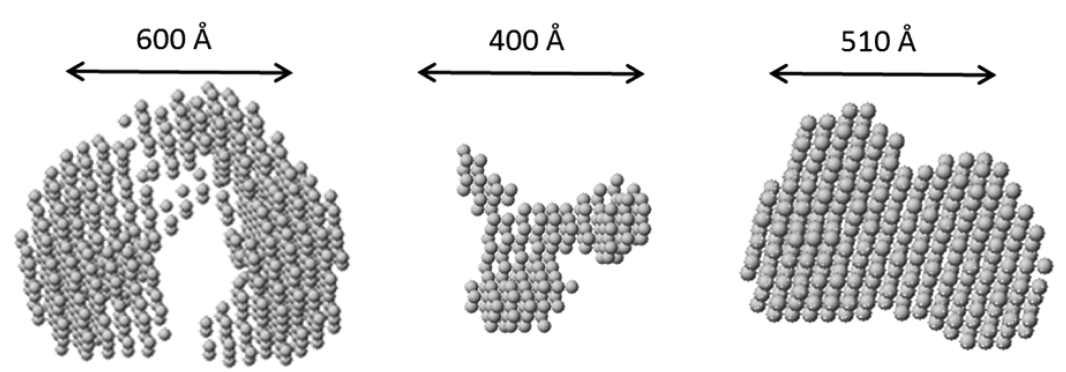

Figure 10. DAMMIN low-resolution structures reconstructed from SAXS patterns for $1 \times 10^{-4} \mathrm{M}$ of $2 \mathrm{a}$ (left) in $\mathrm{H}_{2} \mathrm{O}$, in the presence of 1 equiv of $\mathrm{Zn}^{2+}$ (middle), and in the presence of 1 equiv of $\mathrm{Zn}^{2+}$ and cryptand (right).

Interestingly, the red emission band appears again when a $\mathrm{Zn}^{2+}$ encapsulating agent (1,2-[bis(3-aminopropyl)amine]ethane or 4,7,13,16,21,24-hexaoxa-1,10-diazabicyclo[8.8.8]hexacosane cryptand) is added to the solution (Figure S47), as a result of $\mathrm{Zn}^{2+}$ entrapment. This means that the aggregation state can be directly modulated, being an effective example of adaptive supramolecular systems modulated by external stimuli.

As mentioned before, the intensity reduction of bipyridine resonances for pure $\mathbf{2 b}$ in $\mathrm{D}_{2} \mathrm{O}$ are related to the longer rotational correlation times $\left(\tau_{\mathrm{C}}\right)$ and shorter $T_{2}$ associated with the assembly process. Therefore, this assembly/disassembly process could be followed by monotoring the intensity changes on the NMR spectra. The addition of $\mathrm{Zn}^{2+}$ to a solution of $\mathbf{2 b}$ in $\mathrm{D}_{2} \mathrm{O}$ produced the intensity recovery of the ${ }^{1} \mathrm{H}$ NMR signals of the bipyridyl moiety. The observed chemical shifts of this fragment are in agreement with coordination of the $\mathrm{Zn}^{2+}$ ion to the bipyridine ring in a syn disposition of the $\mathrm{N}$ atoms. ${ }^{48}$ The complexation of $\mathrm{Zn}^{2+}$ cations with an excess of complexing agent cryptand partially reverted the disassembly effects of $\mathrm{Zn}^{2+}$, as observed by the concomitant decrease of the intensity of the aromatic signals in the upper spectrum of Figure 9. The presence of an excess of $\mathrm{Zn}^{2+}$ also shifted the DAPTA proton signals, suggesting a marginal interaction with the tertiary $\mathrm{N}$ atoms or the amide carbonyls of DAPTA (Figure 9).
SAXS experiments performed in the presence of $\mathrm{Zn}^{2+}$ followed by the addition of an encapsulating agent show that the enclosed structures of gold(I) complexes in $\mathrm{H}_{2} \mathrm{O}$ (Figure 10 , left) are disturbed in the presence of the divalent cation (Figure 10, middle), giving rise to smaller structures and going back to aggregation when the encapsulating agent traps the cation and allows the gold(I) complex to self-assemble again (Figures 10, right, and S48-S50).

These processes were observed also for samples in solution under optical microscopy. Well-organized fibrillar aggregates can be detected for an aqueous solution of complexes that disaggregate in the presence of $\mathrm{Zn}^{2+}$ and come back to aggregation when an encapsulating agent is added to the solution (Figure S51).

All in all, we have demonstrated for the first time the selfaggregation of discrete gold(I) complexes in $\mathrm{H}_{2} \mathrm{O}$ that can be externally modulated by the presence/absence of a divalent cation. This process is reversible and has been detected by complementary techniques: NMR, absorption, emission, SAXS, DLS, and optical microscopy in solution.

\section{CONCLUSIONS}

Gold(I) alkynyl complexes containing bipyridine and terpyridyne $\pi$ systems and water-soluble phosphines (PTA and DAPTA) self-assemble in $\mathrm{H}_{2} \mathrm{O}$ and DMSO, as shown by SAXS, 
NMR, and DLS, with very distinct luminescence displayed in both solvents.

An exhaustive ${ }^{1} \mathrm{H}$ NMR study performed with different $\mathrm{D}_{2} \mathrm{O} / \mathrm{DMSO}$ mixtures indicates the presence of two different assembly modes in the aggregates: chain assemblies, which are based mainly on aurophilic interactions, and stacked assemblies, which are based on $\mathrm{Au} \cdots \pi$ interactions, which are confirmed by density functional theory calculations carried out in both solvents. The initial aggregates of nanometer size merge with time to the formation of fibers. This process is promoted by the presence of $\mathrm{H}_{2} \mathrm{O}$.

Bipyridine and terpyridine groups can complex metal cations, leading to the disassembly of aggregates in the presence of $\mathrm{Zn}^{2+}$. This process can be reverted by the addition of complexing agents that sequester $\mathrm{Zn}^{2+}$.

The supramolecular assemblies respond to the metal-ion content by significant changes in both the morphology and luminescence. On a speculative note, the system can constitute the basis of a supramolecular adaptative system toward the presence of metal cations and biological macromolecules able to compete for metal complexation in cells.

\section{ASSOCIATED CONTENT}

\section{S Supporting Information}

The Supporting Information is available free of charge on the ACS Publications website at DOI: 10.1021/acs.inorgchem.7b02343.

High-resolution ESI-MS spectra, 1D and 2D NMR data, UV-visible and luminescent spectra, SAXS data, DLS data, fluorescence and optical microscopy images of the compounds at different conditions, schemes of the synthesis of the complexes and precursors, and tables with NMR data and theoretical calculation parameters (PDF)

\section{AUTHOR INFORMATION}

\section{Corresponding Authors}

*E-mail: lima@fct.unl.pt.

*E-mail: laura.rodriguez@qi.ub.es. Tel.: +34 934039130.

\section{ORCID}

Ignacio Alfonso: 0000-0003-0678-0362

Yolanda Pérez: 0000-0003-3767-5346

João Carlos Lima: 0000-0003-0528-1967

Laura Rodríguez: 0000-0003-1289-1587

\section{Notes}

The authors declare no competing financial interest.

\section{ACKNOWLEDGMENTS}

The authors are grateful to the Ministry of Economy, Industry and Competitiveness of Spain (AEI/FEDER, UE Projects CTQ2016-76120-P, CTQ2015-65040-P, and CTQ201570117-R). This work was also supported by the Associated Laboratory for Sustainable Chemistry, Clean Processes and Technologies, LAQV, which is financed by national funds from FCT/MEC (UID/QUI/50006/2013) and cofinanced by the ERDF under the PT2020 Partnership Agreement (POCI-010145-FEDER-007265). The IQAC NMR Facility $500 \mathrm{MHz}$ spectrometer and cryoprobe were funded by the CSIC13-4E2076 MINECO-FEDER grant. SAXS experiments were performed at the NCD-BL11 beamline of the ALBA Synchrotron Light Facility in collaboration with the ALBA staff. A.J.M. thanks the FCT for a postdoctoral grant (SFRH/ BPD/69210/2010). This research was supported by a Marie Curie Intra European Fellowship within the 7th European Community Framework Programme (to R.G.). We also thank L. Giménez and I. Brea for their help on the synthesis of the ligands.

\section{REFERENCES}

(1) Mayoral Muñoz, M. J.; Fernández, G. Metallosupramolecular amphiphilic $\pi$-systems. Chem. Sci. 2012, 3, 1395.

(2) Sun, Q.-F.; Iwasa, J.; Ogawa, D.; Ishido, Y.; Sato, S.; Ozeki, T.; Sei, Y.; Yamaguchi, K.; Fujita, M. Self-assembled M24L48 polyhedra and their sharp structural switch upon subtle ligand variation. Science 2010, 328, 1144 .

(3) Chui, S. S. Y.; Ng, M. F. Y.; Che, C.-M. C.-M. Structure Determination of Homoleptic AuI, AgI, and CuI Aryl/Alkylethynyl Coordination Polymers by X-ray Powder Diffraction. Chem. - Eur. J. 2005, 11, 1739.

(4) Chow, A.L.-F.; So, M.-H.; Lu, W.; Zhu, N.; Che, C.-M. Synthesis, Photophysical Properties, and Molecular Aggregation of Gold(I) Complexes Containing Carbon-Donor Ligands. Chem. Chem. - Asian J. 2011, 6, 544.

(5) Lin, Q.; Yang, Q.-P.; Sun, B.; Fu, Y.-P.; Zhu, X.; Wei, T.-B.; Zhang, Y.-M. Competitive coordination control of the AIE and micro states of supramolecular gel: an efficient approach for reversible dualchannel stimuli-response materials. Soft Matter 2014, 10, 8427.

(6) Lima, J. C.; Rodríguez, L. Applications of gold(I) alkynyl systems: a growing field to explore. Chem. Soc. Rev. 2011, 40, 5442.

(7) Pinto, A.; Svahn, N.; Lima, J. C.; Rodríguez, L. Aggregation induced emission of gold(I) complexes in water or water mixtures. Dalton Trans. 2017, 46, 11125.

(8) Gavara, R.; Llorca, J.; Lima, J. C.; Rodríguez, L. A luminescent hydrogel based on a new $\mathrm{Au}(\mathrm{I})$ complex. Chem. Commun. 2013, 49, 72.

(9) Aguiló, E.; Gavara, R.; Lima, J. C.; Llorca, J.; Rodríguez, L. From $\mathrm{Au}(\mathrm{I})$ organometallic hydrogels to well-defined $\mathrm{Au}(0)$ nanoparticles. $J$. Mater. Chem. C 2013, 1, 5538.

(10) Moro, A. J.; Rome, B.; Aguiló, E.; Arcau, J.; Puttreddy, R.; Rissanen, K.; Lima, J. C.; Rodríguez, L. A coumarin based gold(I)alkynyl complex: a new class of supramolecular hydrogelators. Org. Biomol. Chem. 2015, 13, 2026.

(11) Aguiló, E.; Gavara, R.; Baucells, C.; Guitart, M.; Lima, J. C.; Llorca, J.; Rodríguez, L. Tuning supramolecular aurophilic structures: the effect of counterion, positive charge and solvent. Dalton Trans. 2016, 45, 7328 .

(12) Chan, A. K.-W.; Lam, W. H.; Tanaka, Y.; Wong, K. M.-C.; Yam, V. W.-W. Multiaddressable molecular rectangles with reversible hostguest interactions: Modulation of $\mathrm{pH}$-controlled guest release and capture. Proc. Natl. Acad. Sci. U. S. A. 2015, 112, 690.

(13) Aida, T.; Meijer, E. W.; Stupp, S. I. Functional supramolecular polymers. Science 2012, 335, 813.

(14) Hubbell, J. A.; Chilkoti, A. Chemistry. Nanomaterials for drug delivery. Science 2012, 337, 303.

(15) Bähring, S.; Martín-Gomis, L.; Olsen, G.; Nielsen, K. A.; Kim, D. S.; Duedal, T.; Sastre-Santos, A.; Jeppesen, J. O.; Sessler, J. L. Design and Sensing Properties of a Self-Assembled Supramolecular Oligomer. Chem. - Eur. J. 2016, 22, 1958.

(16) (a) Arcau, J.; Andermark, V.; Aguiló, E.; Gandioso, A.; Moro, A.; Cetina, M.; Lima, J. C.; Rissanen, K.; Ott, I.; Rodríguez, L. Luminescent alkynyl-gold(I) coumarin derivatives and their biological activity. Dalton Trans. 2014, 43, 4426. (b) Gavara, R.; Aguiló, E.; Schur, J.; Llorca, J.; Ott, I.; Rodríguez, L. Study of the effect of the chromophore and nuclearity on the aggregation and potential biological activity of gold(I) alkynyl complexes. Inorg. Chim. Acta 2016, 446, 189. (c) Meyer, A.; Gutiérrez, A.; Ott, I.; Rodríguez, L. Phosphine-bridged dinuclear gold(I) alkynyl complexes: Thioredoxin reductase inhibition and cytotoxicity. Inorg. Chim. Acta 2013, 398, 72. 
(17) Grosshenny, V.; Ziessel, R. Synthesis and properties of novel ditopic polypyridine ligands bridged by one and two acetylenic bonds. Tetrahedron Lett. 1992, 33, 8075.

(18) Ferrer, M.; Giménez, L.; Gutiérrez, A.; Lima, J. C.; Rodríguez, L.; Martínez, M.; Martín, A.; Puttreddy, R.; Rissanen, K. Polypyridylfunctionalizated alkynyl gold(I) metallaligands supported by tri- and tetradentate phosphanes. Dalton Trans. 2017, 46, 13920.

(19) Constable, E. C.; Housecroft, C. E.; Kocik, M. K.; Zampese, J. A. Photoactive building blocks for coordination complexes: Gilding 2,2':6', 2"'-terpyridine. Polyhedron 2011, 30, 2704.

(20) Vicente, J.; Gil-Rubio, J.; Barquero, N.; Jones, P. G.; Bautista, D. Synthesis of Luminescent Alkynyl Gold Metalaligands Containing 2,2'-Bipyridine-5-yl and 2,2':6',2'-Terpyridine-4-yl Donor Groups. Organometallics 2008, 27, 646.

(21) Aguilar, J. A.; Nilsson, M.; Bodenhausen, G.; Morris, G. A. Spin echo NMR spectra without J modulation. Chem. Commun. 2012, 48, 811.

(22) Johnson, C. S. Diffusion ordered nuclear magnetic resonance spectroscopy: principles and applications. Prog. Nucl. Magn. Reson. Spectrosc. 1999, 34, 203.

(23) Nilsson, M. The DOSY Toolbox: a new tool for processing PFG NMR diffusion data. J. Magn. Reson. 2009, 200, 296.

(24) Macchioni, A.; Ciancaleoni, G.; Zuccaccia, C.; Zuccaccia, D. Determining accurate molecular sizes in solution through NMR diffusion spectroscopy. Chem. Soc. Rev. 2008, 37, 479.

(25) Chen, H. C.; Chen, S. H. Diffusion of crown ethers in alcohols. J. Phys. Chem. 1984, 88, 5118.

(26) Huang, T. C.; Toraya, H.; Blanton, T. N.; Wu, Y. X-ray powder diffraction analysis of silver behenate, a possible low-angle diffraction standard. J. Appl. Crystallogr. 1993, 26, 180.

(27) Kieffer, J.; Karkoulis, D. PyFAI, a versatile library for azimuthal regrouping. J. Phys.: Conf. Ser. 2013, 425, 202012.

(28) Konarev, V.; Volkov, V. V.; Sokolova, A. V.; Koch, M. H. J.; Svergun, D. I. PRIMUS: a Windows PC-based system for small-angle scattering data analysis. J. Appl. Crystallogr. 2003, 36, 1277.

(29) Svergun, D. I. Determination of the regularization parameter in indirect-transform methods using perceptual criteria. J. Appl. Crystallogr. 1992, 25, 495.

(30) (a) Svergun, D. I. Restoring Low Resolution Structure of Biological Macromolecules from Solution Scattering Using Simulated Annealing. Biophys. J. 1999, 76, 2879. (b) Krebs, A.; Durchschlag, H.; Zipper, P. Small Angle X-Ray Scattering Studies and Modeling of Eudistylia vancouverii Chlorocruorin and Macrobdella decora Hemoglobin. Biophys. J. 2004, 87, 1173.

(31) te Velde, G.; Bickelhaupt, F. M.; Baerends, E. J.; Fonseca Guerra, C.; van Gisbergen, S. J. A.; Snijders, J. G.; Ziegler, T. Chemistry with ADF. J. Comput. Chem. 2001, 22, 931.

(32) Grimme, S.; Ehrlich, S.; Goerigk, L. Effect of the damping function in dispersion corrected density functional theory. J. Comput. Chem. 2011, 32, 1456.

(33) van der Wijst, T.; Fonseca Guerra, C.; Swart, M.; Bickelhaupt, F. M.; Lippert, B. A Ditopic Ion-Pair Receptor Based on Stacked Nucleobase Quartets. Angew. Chem., Int. Ed. 2009, 48, 3285.

(34) Klamt, A. Conductor-like Screening Model for Real Solvents: A New Approach to the Quantitative Calculation of Solvation Phenomena. J. Phys. Chem. 1995, 99, 2224.

(35) Pye, C. C.; Ziegler, T. An implementation of the conductor-like screening model of solvation within the Amsterdam density functional package. Theor. Chem. Acc. 1999, 101, 396.

(36) Swart, M.; Rösler, E.; Bickelhaupt, F. M. Proton Affinities in Water of Maingroup-Element Hydrides - Effects of Hydration and Methyl Substitution. Eur. J. Inorg. Chem. 2007, 2007, 3646.

(37) Riley, K. E.; Vondrasek, J.; Hobza, P. Performance of the DFTD method, paired with the PCM implicit solvation model, for the computation of interaction energies of solvated complexes of biological interest. Phys. Chem. Chem. Phys. 2007, 9, 5555.

(38) Jiang, T.; Lu, N.; Hang, Y.; Yang, J.; Mei, J.; Wang, J.; Hua, J.; Tian, H. Dimethoxy triarylamine-derived terpyridine-zinc complex: a fluorescence light-up sensor for citrate detection based on aggregationinduced emission. J. Mater. Chem. C 2016, 4, 10040.

(39) Tatikonda, R.; Bhowmik, S.; Rissanen, K.; Haukka, M.; Cametti, M. Metallogel formation in aqueous DMSO by perfluoroalkyl decorated terpyridine ligands. Dalton Trans. 2016, 45, 12756.

(40) Wang, M.; Wang, K.; Wang, C.; Huang, M.; Hao, X.-Q.; Shen, M.-Z.; Shi, G.-Q.; Zhang, Z.; Song, B.; Cisneros, A.; Song, M.-P.; Xu, B.; Li, X. Self-Assembly of Concentric Hexagons and Hierarchical SelfAssembly of Supramolecular Metal-Organic Nanoribbons at the Solid/Liquid Interface. J. Am. Chem. Soc. 2016, 138, 9258.

(41) Cámara, V.; Barquero, N.; Bautista, D.; Gil-Rubio, J.; Vicente, J. Assembly of Heterometallic Rigid-Rod Complexes and Coordination Oligomers from Gold(I) Metalloligands. Inorg. Chem. 2015, 54, 6147.

(42) Koshevoy, I. O.; Koskinen, L.; Smirnova, E. S.; Haukka, M.; Pakkanen, T. A.; Melnikov, A. S.; Tunik, S. P. Synthesis, structural characterization and luminescence studies of di- and trinuclear gold(I) alkynyl-phosphine complexes. Z. Anorg. Allg. Chem. 2010, 636, 795.

(43) Castellano, S.; Günther, H.; Ebersole, S. Nuclear Magnetic Resonance Spectra of 2,2'-Bipyridyl. J. Phys. Chem. 1965, 69, 4166.

(44) Gavara, R.; Aguiló, E.; Fonseca Guerra, C.; Rodríguez, L.; Lima, J. C. Thermodynamic Aspects of Aurophilic Hydrogelators. Inorg. Inorg. Chem. 2015, 54, 5195.

(45) Shiotsuka, M.; Nishiko, N.; Keyaki, K.; Nozaki, K. Construction of a photoactive supramolecular system based on a platinum(II) bisacetylide building block incorporated into a ruthenium(II) polypyridyl complex. Dalton Trans. 2010, 39, 1831.

(46) Xu, H. B.; Zhang, L. Y.; Ni, J.; Chao, H. Y.; Chen, Z. N. Conformation Changes and Luminescent Properties of Au-Ln ( $\mathrm{Ln}=$ $\mathrm{Nd}, \mathrm{Eu}, \mathrm{Er}, \mathrm{Yb}$ ) Arrays with 5-Ethynyl-2,2'-Bipyridine. Inorg. Inorg. Chem. 2008, 47, 10744.

(47) Rodríguez, L.; Ferrer, M.; Crehuet, R.; Anglada, J.; Lima, J. C. Correlation between Photophysical Parameters and Gold-Gold Distances in Gold(I) (4-Pyridyl)ethynyl Complexes. Inorg. Chem. 2012, 51, 7636

(48) Pazderski, L.; Pawlak, T.; Sitkowski, J.; Kozerski, L.; Szlyk, E. 1H NMR assignment corrections and 1H, 13C, 15N NMR coordination shifts structural correlations in $\mathrm{Fe}(\mathrm{II}), \mathrm{Ru}(\mathrm{II})$ and $\mathrm{Os}(\mathrm{II})$ cationic complexes with 2,2'-bipyridine and 1,10-phenanthroline. Magn. Reson. Chem. 2010, 48, 450. 